\title{
Dimerization of Abietic Acid for the Design of Renewable Polymers from ADMET
}

\author{
Audrey Llevot ${ }^{a, b}$, Etienne Grau ${ }^{a, b}$, Stéphane Carlotti ${ }^{a, b}$, Stéphane Grelier ${ }^{a, b}$ and Henri \\ Cramail $^{a, b^{*}}$
}

${ }^{a}$ Univ. de Bordeaux, Laboratoire de Chimie des Polymères Organiques, UMR 5629, IPB/ENSCBP, 16 avenue Pey-Berland, F-33607, Pessac cedex, France

${ }^{b}$ Centre National de la Recherche Scientifique, Laboratoire de Chimie des Polymères Organiques, UMR 5629, F-33607, Pessac cedex, France, Email : cramail@enscbp.fr

\begin{abstract}
Cationic dimerization of abietic acid, a resource from tall oil or pines, was investigated and optimized. Diacid dimers were obtained in good yields and isolated from abietic acid. These diacid dimers were then esterified with undecenol to give bisunsaturated dimers. The latter were then homopolymerized or copolymerized with undecenyl undecenoate thanks to ADMET methodology, leading to thermoplastic polymers with molar mass up to 40000 $\mathrm{g} / \mathrm{mol}$. While the copolymers exhibit melting points around $50^{\circ} \mathrm{C}$, the homopolymer of abietic acid dimer is fully amorphous with a $\mathrm{Tg}$ around $100^{\circ} \mathrm{C}$.
\end{abstract}

\section{Keywords}

Abietic acid dimers, vegetable oil, thermoplastic polymers, ADMET

\section{Introduction}

Synthetic polymers, essential in our daily life, are mainly produced from petrol. The partial replacement of fossil feedstock by renewable resources attracts today a thriving interest due to the petrol depletion and the growth of environmental concerns. ${ }^{1,2}$ In this purpose, new molecules and monomers issued from available biomass have to be developed. ${ }^{3-7}$ Vegetable oils have been intensively studied, as they enable the synthesis of novel renewable polymers that mimic synthetic ones. ${ }^{8}$ Due to their inherent aliphatic structures, polymers obtained from fatty acid derivatives generally exhibit 'limited' thermo-mechanical properties. ${ }^{9}$ It is thus important to investigate other bio-based molecular platforms to broaden the palette of renewable polymers. Molecules such as sugars ${ }^{10}$ and wood derivatives (e.g. terpenes, rosin, lignin, cellulose) ${ }^{11-13}$ are very important feedstocks to design novel monomers for the 
synthesis of polymeric materials with original features and properties.

Bioresources derived from pines have aroused interest due to their abundance, low cost and easy chemical modifications. ${ }^{14}$ Rosin, which total annual production is over 1 million ton, is obtained through the process of distillation of pine resin or tall oil (a by-product of the Kraft process) or from aged pine stumps. ${ }^{15}$ Rosin is traditionally used in biomedical applications (e.g. ointment, glazing agent), coating, printing inks and adhesives. It is composed of $10-20 \%$ of neutral compounds (terpens) and $80-90 \%$ of resin acids, a mixture of isomeric organic acids from abietic acid (40-60\%). Abietic acid, with its rigid tricyclic skeleton possessing two double bonds and a carboxylic functional group (scheme 1) appears to be an interesting platform towards stiff bio-based polymers. ${ }^{16}$

Only few examples of rosin derivative polymerizations have been reported. On the first hand, resin acids are polymerized, either after converting to vinyl, allyl ester or acrylic group which can undergo radical polymerization to prepare well-defined side chain rosinbased polymers ${ }^{17-20}$ with high molar mass and low Tg, or via the Diels-Alder reaction between levopimaric acid and maleic anhydride (or acrylic acid), to yield difunctional monomers and the main chain rosin derived polymers thereof. ${ }^{21-25}$ On the second hand, Tang et al ${ }^{26}$ recently reported the copolymerization of resin acid derivatives with fatty ester derivatives by ADMET polymerization leading to polymers with a molar mass of $9200 \mathrm{~g} / \mathrm{mol}$ and a $\mathrm{Tg}$ of $5^{\circ} \mathrm{C}$. It is noteworthy to mention that all the main chain abietic acid-based polymers exhibit low molar mass presumably due to steric hindrance and/or impurities of the abietic acid.

Another interesting way to obtain difunctional compounds is the dimerization of abietic acid. However, rosin cationic dimerization with a Lewis acid leads to ill-defined structures containing mainly dimers and trimers of abietic acid. ${ }^{27}$ Such dimerized rosin is a commercially important product which finds application in adhesives, films, varnishes and even into formulation of transdermal drug delivery system, because of its excellent film forming. ${ }^{28}$ Recently, we reported the synthesis of epoxy resins from oligomerized rosin as DGEBA substituted. ${ }^{29,30}$

Since the work of Brus, ${ }^{31}$ tremendous efforts have been realized to optimize the dimerization process of abietic acid ${ }^{32}$ and to identify the structure of the dimers formed. ${ }^{33,34}$ Zinkel et $a l^{35}$ demonstrated, by Gas Chromatography (GC), the formation of at least 40 different dimeric compounds and isolated six of them at the milligram scale; only one structure was partially characterized by X-ray (Scheme 1). ${ }^{36}$ To the best of our knowledge, no abietic acid dimers were used for the synthesis of thermoplastic polymers.

In this study, abietic acid has been dimerized and the resulting dimers efficiently 
isolated from the crude mixture. This purification, in which impurities and unreacted abietic acid were removed, is a key step for the synthesis of high molar mass polymers. Close investigation of the number of dimers and their structures as a function of the reaction conditions is given through GC, NMR and IR analyses. In a first step, polycondensation of abietic acid dimer with diols was carried out yielding only oligomers. Then, the dimers were esterified with undecenol in order to introduce accessible reactive double bonds, followed by ADMET copolymerization of the unsaturated dimers with undecenyl undecenoate. The thermo-mechanical properties of the polymers so-formed are also discussed.

(a)
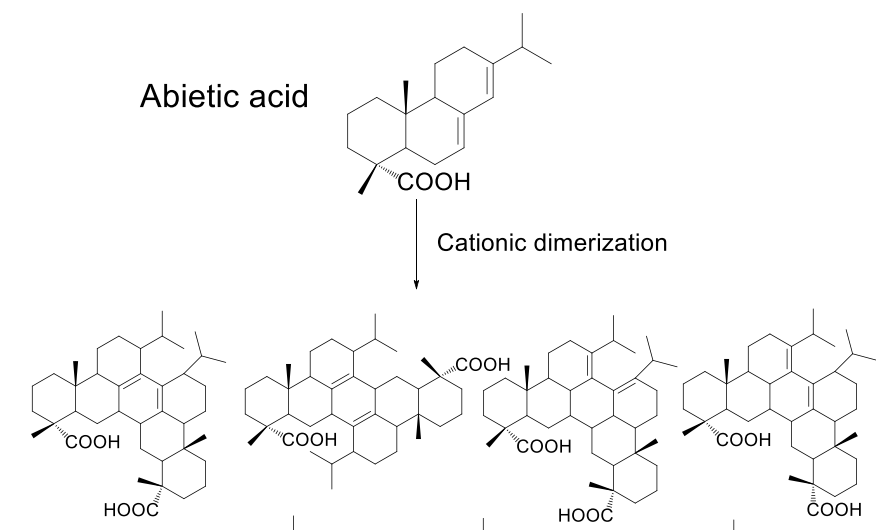

(b)

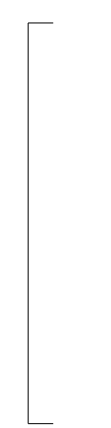

(c)
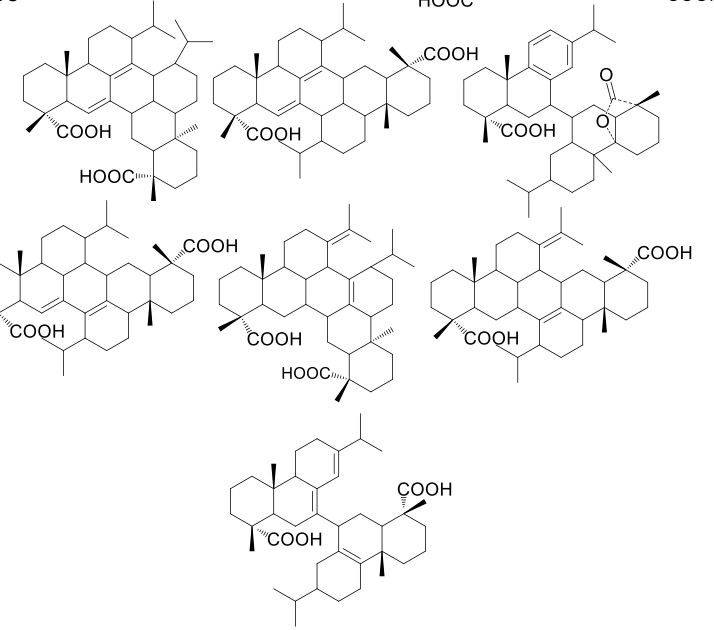

Scheme 1 Abietic dimer structures suggested in literature: (a) abietic acid structures previously suggested by Brus, Morillon and Bardyshev ${ }^{31,33,34}$ (b) abietic dimers proposed by Zinkel from NMR and IR data ${ }^{35}$ and (c) dimer structure partially characterized by X-ray by Zinkel $^{36}$

\section{Experimental}

\section{Materials}

Methyl 10-undecenoate (98.0\%) was supplied by TCI Europe, 10-undecenol (99\%), abietic acid (85\%), N,N'-Diisopropylcarbodiimide (DIPC 99\%), p-toluenesulfonic acid monohydrate 
(99\%), benzylidene-bis(tricyclohexylphosphine)dichlororuthenium (Grubbs 1st generation metathesis catalyst), 1,5,7-triazabicyclo[4.4.0]dec-5-ene (TBD, 98\%) and zinc acetate were purchased at Sigma Aldrich. Sulfuric acid (98\%), 4-dimethylaminopyridine (99\%) and titanium butoxide (99\%) were bought from Fisher. Polarclean (methyl-5-(dimethylamino)-2methyl-5-oxopentanoate) was supplied by Solvay and antimony trioxide (99.6\%) by Alfa Aesar. All products and solvents (reagent grade) were used as received.

\section{Abietic acid dimer synthesis}

A solution of $3 \mathrm{~g}(0,01 \mathrm{~mol})$ of abietic acid in $40 \mathrm{ml}$ of chloroform was mixed with $1.05 \mathrm{ml}(1$ eq) of concentrated sulfuric acid (98\%). The reaction flask was warmed and stirred at $45^{\circ} \mathrm{C}$ in oil bath, under nitrogen flow for 5 hours, after which time the reaction was quenched with 60 $\mathrm{ml}$ of water. Activated carbon was added and filtered in order to eliminate oxidized products. 2.8-3 g of pale yellow solid was obtained after evaporation of the solvent and dried overnight under vacuum at $70^{\circ} \mathrm{C}$.

\section{Abietic acid dimer isolation}

The product was dissolved in a minimum of methanol and injected in a Flash chromatography apparatus from Grace. The constituents were separated on a C18 grafted silica column, using a methanol-water gradient (vide infra) and detected by two UV detectors (wavelengths: 254 and $280 \mathrm{~nm}$ ) and an Evaporating Light Scattering Detector (ELSD). Three fractions corresponding to dehydroabietic acid, isomerized abietic acid and dimers plus trimers were collected.

\section{Abietic methyl ester dimer synthesis}

Abietic acid dimer (3 g, $0.01 \mathrm{~mol}$ of acid functional groups) was dissolved in $50 \mathrm{ml}$ of $\mathrm{CH}_{2} \mathrm{Cl}_{2}$ under stirring. Subsequently p-toluene sulfonic acid/4-dimethylaminopyridine catalyst in a molar ratio 1/1.2 was added. The flask was placed in an ice bath and subsequently an excess of methanol $(0.7 \mathrm{ml}, 0.017 \mathrm{~mol})$ was added to the solution. Finally N,N'-diisopropyl carbodiimide (DIPC, $4.5 \mathrm{ml}, 0.03 \mathrm{~mol}$ ) was added dropwise under stirring. The reaction was left under stirring for 72 hours at room temperature. Afterwards the solution was washed three times with water, dried and the solvent was removed under reduced pressure. The acylurea formed was eliminated by filtration after dissolution of the product in toluene. The brown 
solid formed was dried at $70^{\circ} \mathrm{C}$ under vacuum. Yield: $72 \%$. The purity was confirmed by IR (band at $1720 \mathrm{~cm}-1)$ and by ${ }^{13} \mathrm{C}$ NMR (- $\underline{\mathrm{COOCH}}_{3}-178 \mathrm{ppm}$, , $\left.-\mathrm{COOCH}_{3}-65 \mathrm{ppm}\right)$ analyses.

\section{Abietic acid dimer esterification with undecenol}

Abietic acid dimer (3 g, $0.01 \mathrm{~mol}$ of acid functional groups) was dissolved in $50 \mathrm{ml} \mathrm{of} \mathrm{CH}_{2} \mathrm{Cl}_{2}$ under stirring. Subsequently p-toluene sulfonic acid/4-dimethylaminopyridine catalyst in a molar ratio 1/1.2 was added. The flask was placed in an ice bath and subsequently an excess of undecenol (3 ml, $0.015 \mathrm{~mol})$ was added to the solution. Finally, N,N'-diisopropyl carbodiimide (DIPC, $4.5 \mathrm{ml} 0.03 \mathrm{~mol}$ ) was added dropwise under stirring. The reaction was left under stirring for 72 hours at room temperature. Afterwards the solution was washed three times with water, dried and the solvent was removed under reduced pressure. The product was a yellow brown viscous liquid. The acylurea formed was eliminated by filtration after dissolution of the product in toluene. The remaining reactants were eliminated by silica column purification using dichloromethane/methanol 98/2 eluant. The total removal of undecenol during the purification over column is checked by the disappearance of the peak at $62 \mathrm{ppm}$ in ${ }^{13} \mathrm{C}$ NMR. Yield: $46 \%$. The purity was confirmed by ${ }^{13} \mathrm{C}$ NMR analysis ($\underline{\mathrm{COOCH}}_{2}-178$ ppm, $-\mathrm{COOC} \underline{H}_{2}-65$ ppm, $\mathrm{CH}_{2}=\underline{\mathrm{C}} \mathrm{H}-139$ ppm; $\underline{\mathrm{CH}}_{2}=\mathrm{CH}-114$ ppm).

\section{Synthesis of undecenyl undecenoate}

Undecenol (12.8 g, $0.08 \mathrm{~mol})$ was blended with 10-methylundecenoate (15 g, $0.08 \mathrm{~mol})$. TBD $(5 \% \mathrm{~mol})$ was added as a catalyst. The reaction was performed under a nitrogen flow at $120^{\circ} \mathrm{C}$ for $2 \mathrm{~h}$ then the temperature was increased to $160^{\circ} \mathrm{C}$ for $2 \mathrm{~h}$ more and vacuum was applied for the 2 last hours. Purification over silica was performed using cyclohexane/ethylacetate 94/6 eluant. Yield: 76\%. ${ }^{1} \mathrm{H}$ NMR (400MHz, CDCl3, $\left.\delta(\mathrm{ppm})\right): 5.8\left(\mathrm{~m}, 1 \mathrm{H},-\mathrm{C} \underline{\mathrm{H}}=\mathrm{CH}_{2}\right), 4.9(\mathrm{~m}, 2 \mathrm{H}$, $\left.\mathrm{CH}_{2}=\mathrm{CH}-\right), 4.0$ (t, 2H, - $\left.\underline{\mathrm{H}}_{2} \mathrm{COO}-\right), 2.2$ (t, 2H, - $\left.\mathrm{COOC}_{2}{ }_{2}\right)$.

\section{General procedure for polycondensation reaction of abietic acid dimer}

Diol (1 equivalent) and diester/diacid (1 equivalent via acid base titration) were stirred at $160^{\circ} \mathrm{C}$ for $2 \mathrm{~h}$ under nitrogen flow and at $200^{\circ} \mathrm{C}$ under vacuum for $6 \mathrm{~h}$ in the presence of 1 mol\% of catalyst relative to acid or ester functions for all catalysts excepted for TBD. In this case, the reaction is performed at $120^{\circ} \mathrm{C}$ under vacuum for $24 \mathrm{~h}$. 
Homopolymerization of esterified abietic acid dimer. Esterified abietic acid dimer $(0.2 \mathrm{~g}, 0.22$ mmol) was dissolved in $1 \mathrm{~mL}$ of Polarclean. Grubbs $1^{\text {st }}$ generation $(2 \% \mathrm{~mol})$ was added to the flask. The flask was heated at $80^{\circ} \mathrm{C}$ under vacuum for $8 \mathrm{~h}$. Then $3 \mathrm{ml}$ of ethyl vinyl ether was introduced to the flask to quench the reaction. The final polymer was obtained by reprecipitation in cold methanol.

Copolymerization. Esterified abietic acid dimer $(0.2 \mathrm{~g}, 0.22 \mathrm{mmol})$ and the corresponding amount of undecenyl undecenoate (0.2-0.6-1-1.4-1.8eq) were mixed and dried overnight under vacuum. Grubbs $1^{\text {st }}$ generation catalyst $(2 \%$ mol) was added and the flask was heated at $80^{\circ} \mathrm{C}$ under vacuum for $8 \mathrm{~h} .3 \mathrm{ml}$ of ethyl vinyl ether and $4 \mathrm{~mL}$ of THF were introduced to the flask. The final polymer was obtained by precipitating in cold methanol.

\section{Instrumentations}

${ }^{1} \mathrm{H}-\mathrm{NMR}$ and ${ }^{13} \mathrm{C}-\mathrm{NMR}$ spectra were recorded using a Bruker AC-400 NMR at room temperature, in $\mathrm{CDCl}_{3}$. Analytical GC characterization was carried out with a TRACE GC instrument equipped with 2 different columns and programs: column 1 : CP Sil 8CB (25 m $\times$ $0.32 \mathrm{~mm} \times 0.12 \mu \mathrm{m}$ ), oven temperature program: initial temperature $200{ }^{\circ} \mathrm{C}$, ramp at 15 ${ }^{\circ} \mathrm{C} . \mathrm{min}^{-1}$ to $300{ }^{\circ} \mathrm{C}$, hold for $10 \mathrm{~min}$, ramp at $2{ }^{\circ} \mathrm{C} \cdot \mathrm{min}^{-1}$ to $310^{\circ} \mathrm{C}$, hold for $10 \mathrm{~min}$, or column 2: CP Sil 5CB $(25 \mathrm{~m} \times 0.32 \mathrm{~mm} \times 0.40 \mu \mathrm{m})$, oven temperature program: initial temperature $155{ }^{\circ} \mathrm{C}$, ramp at $15{ }^{\circ} \mathrm{C} \cdot \mathrm{min}^{-1}$ to $300{ }^{\circ} \mathrm{C}$, hold for $10 \mathrm{~min}$, ramp at $2{ }^{\circ} \mathrm{C}$. $\min ^{-1}$ to $310^{\circ} \mathrm{C}$, hold for $10 \mathrm{~min}$, hold for $10 \mathrm{~min}$, using flame ionization detection. The injector transfer line temperature was set to $280{ }^{\circ} \mathrm{C}$. Measurements were performed in split mode using helium as the carrier gas (flow rate $10 \mathrm{~mL} \cdot \mathrm{min}^{-1}$ ). The samples were methylated using TMSH (trimethylsulfonioum hydroxide) $0.2 \mathrm{M}$ in methanol from Macherey-Nagel before GC analysis. HPLC was performed using a Spectra system instrument fitted with a Phenomenex Luna $5 \mu$ C18 100A column and compounds were detected with a Sedere Sedex 85 LT ELSD detector at $40^{\circ} \mathrm{C}(\mathrm{G}=4$, filter $\mathrm{OFF})$.

Size exclusion chromatography (SEC) analysis was performed at room temperature in THF using simultaneous UV and refraction index detections. The elution times were converted to molar mass using a calibration curve based on low dispersity (Mw/Mn) polystyrene (PS) standards. Infrared spectra were obtained on a Bruker-Tensor 27 spectrometer using the attenuated total reflection (ATR) mode. Differential Scanning Calorimetry (DSC) 
measurements were performed on DSC Q100 (TA Instruments). The sample was heated from $-70{ }^{\circ} \mathrm{C}$ to $180{ }^{\circ} \mathrm{C}$ at a rate of $10^{\circ} \mathrm{C} \cdot \mathrm{min}^{-1}$. Consecutive cooling and second heating run were also performed at $10{ }^{\circ} \mathrm{C} \cdot \mathrm{min}^{-1}$. The glass transition temperatures and melting points were calculated from the second heating run. The mechanical properties were measured with a dynamic mechanical thermal analyzer DMA RSA 3 (TA instruments). The sample temperature was modulated from $-80^{\circ} \mathrm{C}$ to $150^{\circ} \mathrm{C}$, at a heating rate of $5^{\circ} \mathrm{C} \cdot \mathrm{min}^{-1}$ and a frequency of $1 \mathrm{~Hz}$. The compression mode was used on a pallet of $5 \mathrm{~mm}$ diameter.

\section{Results and Discussion}

Abietic acid dimer synthesis, purification and structure investigation

Dimerization of abietic acid is a long known reaction taking place through a cationic mechanism ${ }^{31}$. Usually, after reaction, a complex mixture of compounds containing unreacted abietic acid, dimers, and oligomers is obtained. In this paper, we first investigated the dimerization process and focused on the isolation of the dimer fraction from the crude mixture, before its polymerization.

Cationic dimerization of abietic acid was performed in $\mathrm{CHCl}_{3}$ at $45^{\circ} \mathrm{C}$ using sulfuric acid as a catalyst according to the Sinclair et $a l^{25}$ method. The composition of the final solution, before any purification, can be determined by SEC measurements in THF (Figure 1). Three peaks are detected and attributed to abietic acid $(M=302 \mathrm{~g} / \mathrm{mol})$, dimers $(\mathrm{M}=604$ $\mathrm{g} / \mathrm{mol})$ and trimers $(\mathrm{M}=906 \mathrm{~g} / \mathrm{mol})$ of abietic acid which represent respectively $31 \%, 57 \%$, and $12 \%$ of the mixture (for the $85 \%$ pure abietic acid (a)), assuming that the latter possess similar $\mathrm{dn} / \mathrm{dc}$. The dimer yield is function of the composition and purity of the starting abietic acid (Figure 1). Indeed, raw abietic acids, from the distillation of pine resin (c) or tall oil (d), respectively lead to $35 \%$ and $37 \%$ of dimers. This lower efficiency should be due to the impurities present in these raw abietic acids which are respectively neoabietic acid unit (14\%) and dehydroabietic acid unit (36\%) (see SD table S1); moreover in these raw abietic acids, some dimers, already present, could also impact the dimerization process. ${ }^{37}$

Interestingly, not all isomers of abietic acid disfavor the cationic dimerization process. Indeed, the isomerized abietic acid (b) (Figure 1b), obtained as a side product of the abietic acid dimerization, which is composed of a mixture of abietic (54\%), levopimaric and palustric acids (both representing 43\%), leads to higher dimer conversion (75\%). In this case a better selectivity toward dimerization vs oligomerization is also observed. 


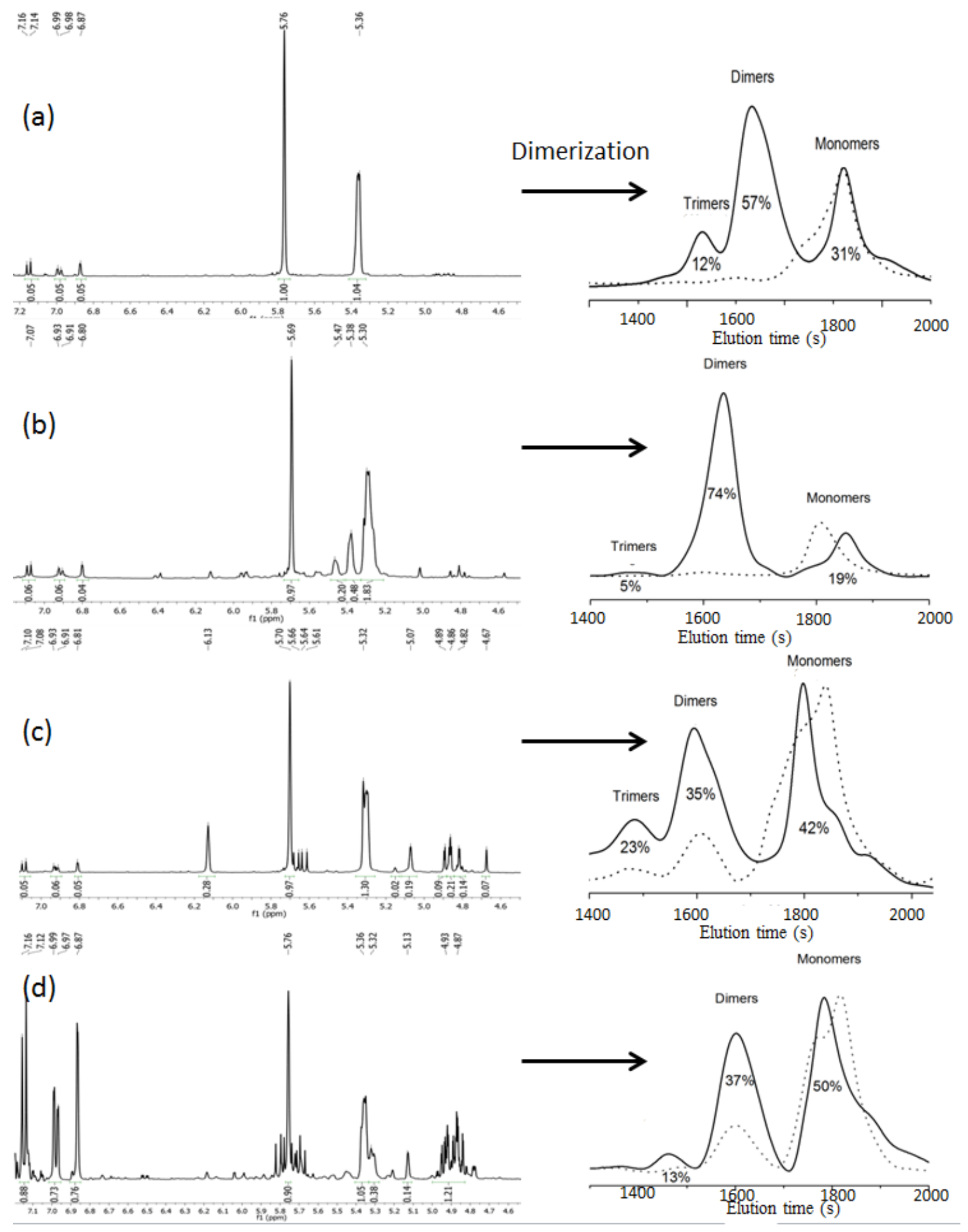

Figure $1{ }^{1} \mathrm{H}$ NMR spectra zoom on the vinylic region of the starting abietic acid and SEC analyses after the dimerization (dot and plain lines correspond respectively to 'before' and 
'after' the dimerization) : (a) 85\% pure abietic acid, (b) pre-isomerized abietic acid, (c) raw abietic acid from pine resin distillation, (d) raw abietic acid from tall oil distillation

Once the dimerization of abietic acid performed, the dimers were isolated from the crude product. In this purpose, several methods have been scrutinized (see Table S2). Only the Thin Layer Chrommatography (TLC) with C18 grafted silica support, using methanol/water as an eluent, presents two clear spots allowing a separation over silica column (Retardation Factor (Rf) around 0.10 and 0.40). High Performance Liquid Chromatography (HPLC) (see SD Figure S2), with a C18 grafted silica column, was performed in order to find the best solvent conditions for the isolation of the dimer compounds. Starting from a $70 \%$ methanol/water solution and gradually increasing the methanol concentration, three separated peaks were observed. A similar profile was observed on the Flash chromatography apparatus (from Grace) after the adaptation of the HPLC conditions (see SD figure S3). Three fractions were collected and analyzed by NMR and SEC in THF (figure 2-4 and SD figure S4). The first two fractions correspond respectively to abietic acid (and its isomers) and dehydroabietic acid, only the third fraction with a molar mass of $600 \mathrm{~g} / \mathrm{mol}$ corresponds to a dimerized abietic acid (see Table 1).

Table 1 Chemical properties of the initial abietic acid (a), the mixture obtained after dimerization (b) and the fractions obtained after Flash Chromatography (c)

\begin{tabular}{|c|c|c|c|c|c|c|c|}
\hline & Sample & $\begin{array}{c}\text { \%mol } \\
\text { Monomer }^{\mathrm{a}}\end{array}$ & $\begin{array}{c}\text { \%mol } \\
\text { Dimer }^{\mathrm{a}}\end{array}$ & $\begin{array}{c}\text { \%mol } \\
\text { Trimer }^{\mathrm{a}}\end{array}$ & $\begin{array}{l}\text { Acid functions } \\
(\mathbf{m m o l} / \mathbf{g})^{\mathbf{b}}\end{array}$ & $\mathrm{M}(\mathrm{g} / \mathrm{mol})^{\mathrm{a}}$ & $\mathbf{F}^{\mathrm{c}}$ \\
\hline (a) & Abietic acid & 74 & 26 & 0 & 3.1 & 380 & 1.2 \\
\hline (b) & $\begin{array}{c}\text { Abietic acid after } \\
\text { dimerisation }\end{array}$ & 31 & 57 & 12 & 3.3 & 550 & 1.8 \\
\hline \multirow{3}{*}{ (c) } & $\begin{array}{c}\text { Fraction } 1 \\
\text { Dehydroabietic acid }\end{array}$ & 100 & 0 & 0 & 3.3 & 300 & 1.0 \\
\hline & \begin{tabular}{|c|} 
Fraction 2 \\
Pre-isomerized \\
abietic acid
\end{tabular} & 100 & 0 & 0 & 3.7 & 302 & 1.1 \\
\hline & $\begin{array}{c}\text { Fraction } 3 \\
\text { Dimers + trimers }\end{array}$ & 0 & 91 & 9 & 3.2 & 630 & 2.0 \\
\hline
\end{tabular}

a Determined by SEC measurements with a RI detector, ${ }^{b}$ Determined by $\mathrm{KOH}$ titration, ${ }^{\mathrm{c}} \mathrm{F}$, functionality, number of acid functions which can participate in the polymerization

Indeed, all the peaks of the NMR spectrum of the first fraction are attributed to pure dehydroabietic acid (Figure 2). The second fraction is a mixture of abietic acid (54\%), and 
abietic acid isomers: levopimaric acid and palustric acid (which represent together $43 \%$ ) and dehydroabietic acid (3\%). The composition of the last fraction cannot be revealed by the interpretation of its NMR spectrum (Figure 4), but its SEC analysis shows the disappearance of the monomer peak (see SD figure S4). An acid-base titration with a $\mathrm{KOH}$ solution and the average molar mass determined by SEC allow us the calculation of an acid derivative functionality of 2.0 for this fraction. The yield of dimers and trimers (fraction 3), isolated from the crude mixture represents 35 weight $\%$.

Gas Chromatography (GC), was then performed in order to confirm the dimer purification efficiency (Figure 5). After dimerization, the appearance of the peaks after 15 min enables to determine the dimer region of the chromatogram (trimers are not detected because of their higher molar mass). Moreover the disappearance of abietic acid (6.3 min) as well as the production of dehydroabietic acid ( $5.8 \mathrm{~min}$ ) can be observed (confirmed by pure product GC analysis, figure 5). After purification by flash chromatography, the dimer area represents $98 \%$ of the chromatogram total area.

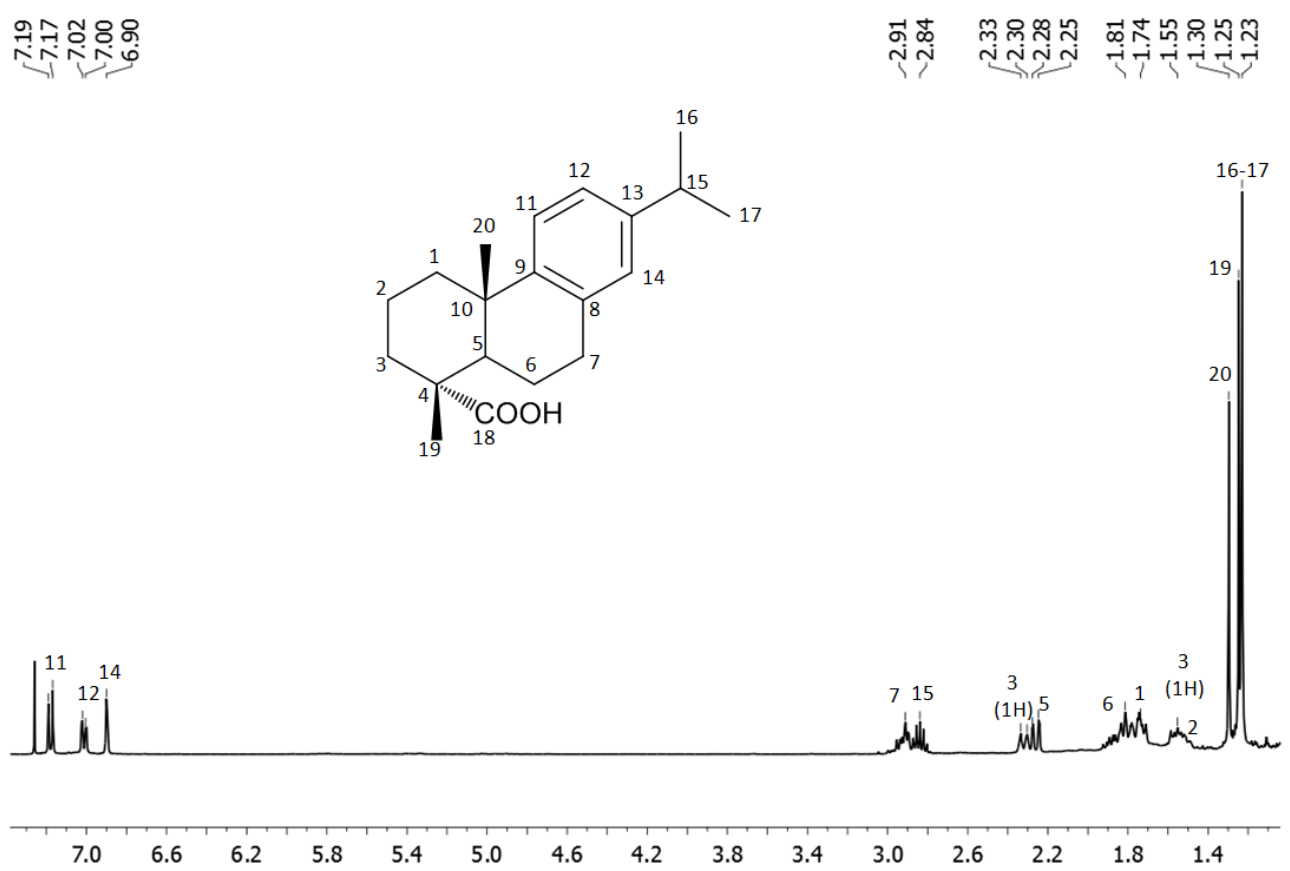

Figure 2: ${ }^{1} \mathrm{H}$ NMR spectrum of fraction 1 (dehydroabietic acid) in $\mathrm{CDCl}_{3}$ 


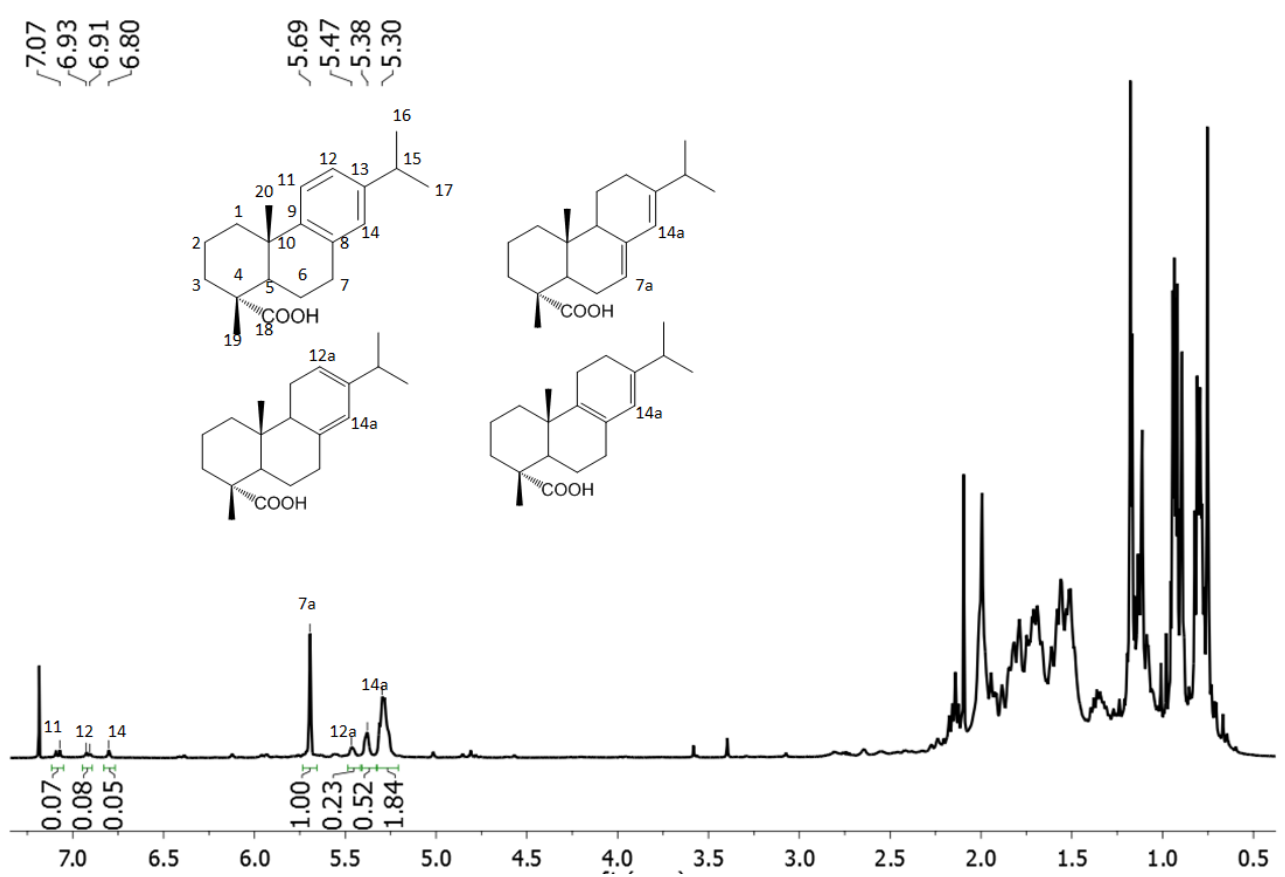

Figure 3: ${ }^{1} \mathrm{H}$ NMR spectrum of fraction 2 (pre-isomerized abietic acid) in $\mathrm{CDCl}_{3}$

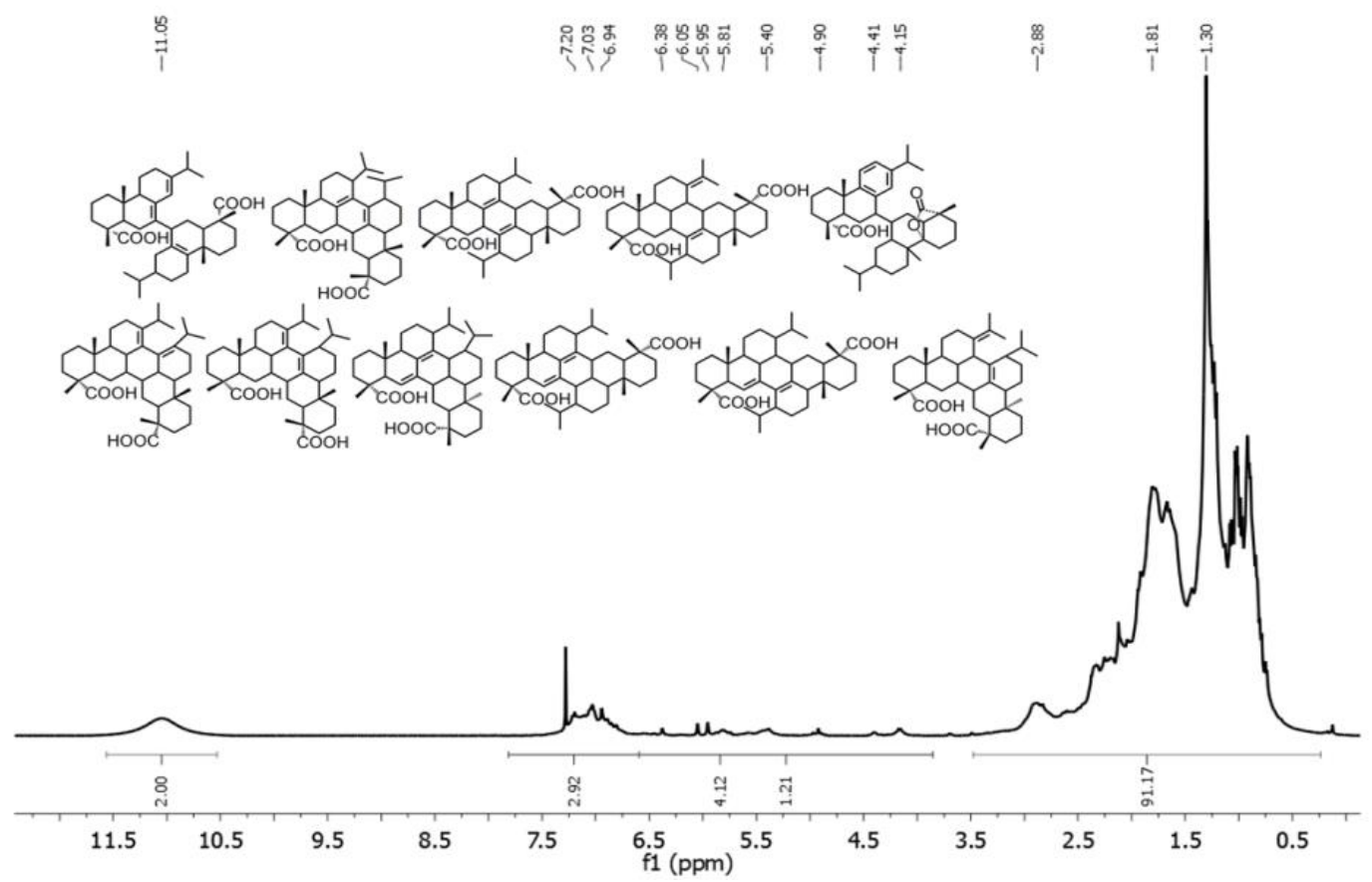

Figure 4: ${ }^{1} \mathrm{H}$ NMR spectrum of fraction 3 (dimers + trimers of abietic acid) in $\mathrm{CDCl}_{3}$ 


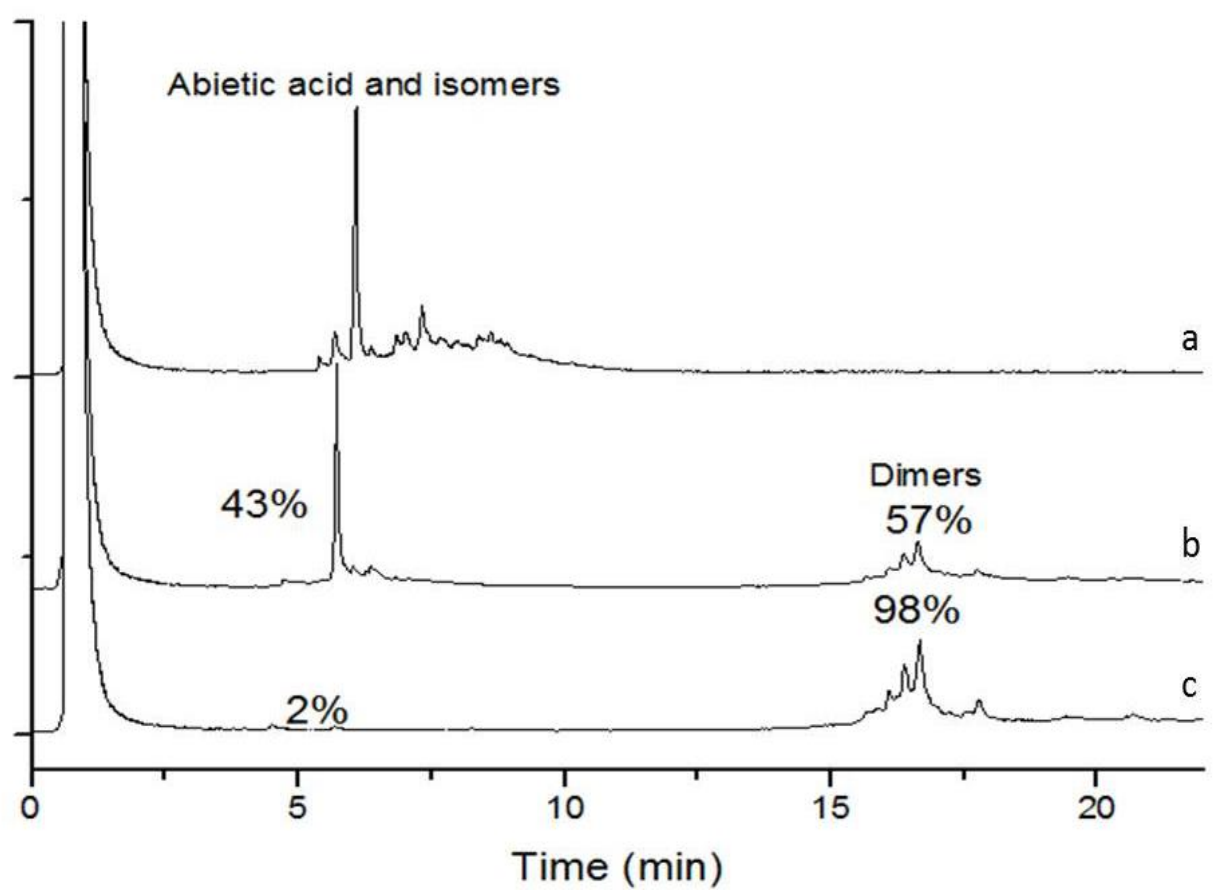

Figure 5 GC analyses of abietic acid (a), abietic acid dimers before and after purification (b and c) (using column 1)

Interestingly this analysis shows several peaks in the dimer region, revealing the formation of various molecules (see SD Figure S5).

Indeed, several structures have been already proposed in literature but none have been fully characterized ${ }^{35,36}$ and the mechanism of the cationic dimer formation has not been elucidated yet. Thus, the formed dimers possess an unknown structure. However, a closer look to ${ }^{1} \mathrm{H}$ NMR (Figure 4) reveals some characteristics of the dimer structures. Some dimers present an aromatic ring (6.7-7.3 ppm signals), isomerized abietic acid unit (5.3-5.9 ppm) and neoabietic acid unit $(6.1 \mathrm{ppm})$. Moreover, the ratio of vinylic proton drops drastically compared to abietic acid (7.4 to 4.4\%) indicating that tetrasubstituted double bonds are present in the dimer structures. Finally, some dimers bear one carboxyl group in the form of lactone ( $40 \%$ lactone vs $60 \%$ of carboxylic acid), as show the band at $1772 \mathrm{~cm}^{-1}$ on the dimer IR spectrum and the pics between 183 and $184 \mathrm{ppm}$ on the ${ }^{13} \mathrm{C}$ NMR spectrum, respectively (see SD figures S6 and S9).

The dimerization process was studied further using different temperatures and Lewis acids in order to improve the selectivity of the reaction. The dimerization conversion and number of dimer structures was determined by GC (see SD table S3, Figure S7). The highest yields of dimers (35-60\%) were reached with sulfuric acid, but between 8 to 13 structures were observed. Since Gigante et al. ${ }^{36}$ observed the 
crystallization of one of the dimer when the dimerization is catalyzed by p-toluenesulfonic acid (PTSA), samples with different amounts of PTSA were prepared and analyzed (see SD figure S8). The dimer yield is very low, around 3\% but the selectivity can be improved for high content in PTSA. Finally, the dimer composition is different as a function of time. Indeed, after $3 \mathrm{~h}$ of reaction, the dimer with a retention time of $16.5 \mathrm{~min}$ is a majority but after one week, the one with a retention time at 17.8 min becomes a majority (Figure 6). Unfortunately due to the low yield, it was impossible to isolate them for further structure analysis. Finally, increasing the temperature to $45^{\circ} \mathrm{C}$ improves the selectivity for both sulfuric acid and PTSA.

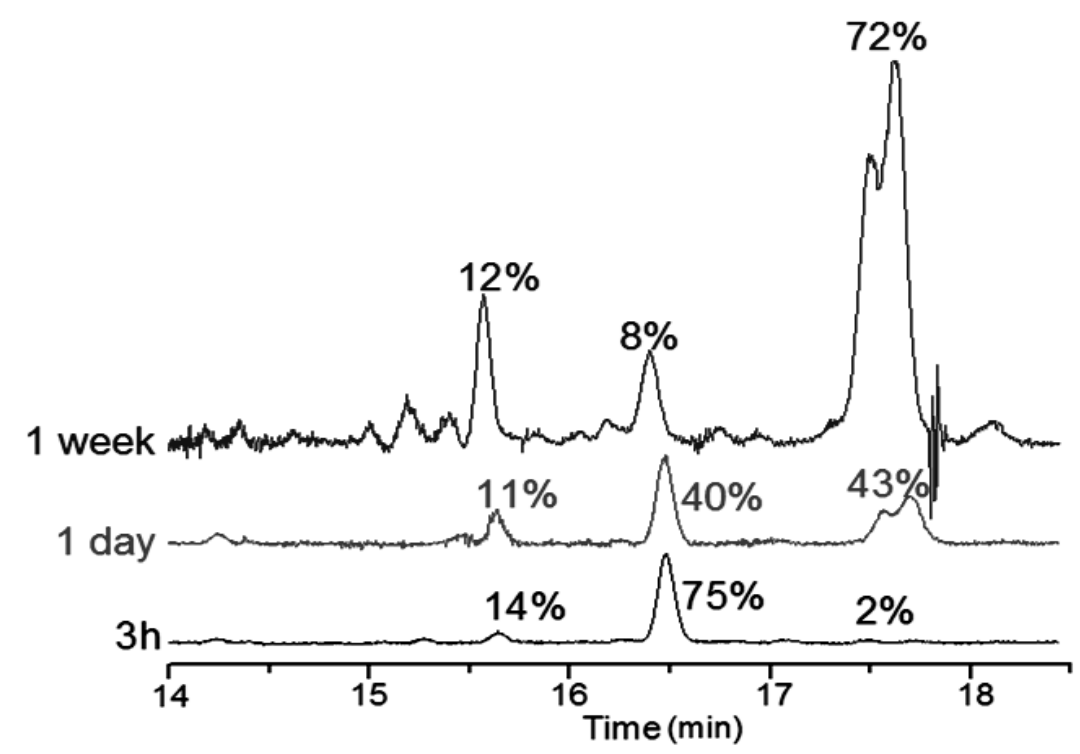

Figure 6 GC analyses of abietic acid dimerization, catalyzed by p-toluenesulfonic acid at $20^{\circ} \mathrm{C}$; zoom on the dimeric part (using column 1, see experimental part)

To conclude this part, these results permit to have some clues about the reaction of sulfuric acid with abietic acid, where three distinctive process seem to take place: dehydrogenation (fraction 1), isomerization (fraction 2), and dimerization (fraction 3) of abietic acid leading to a complex mixture. Neither the Lewis acid catalyst nor the temperature allow obtaining high yield/high selectivity dimerization of abietic acid. The method to reach high conversion in dimer formation is the Sinclair's method (sulfuric acid at $45^{\circ} \mathrm{C}$ ) and was followed for the rest of the study. The main point of this part remains the isolation of abietic acid dimers (and small amount of trimers) from the crude mixture, fraction 3 which, with a functionality, $\mathrm{F}$, in acidic function of 2 , is prone for polymerization. 


\section{Abietic acid dimer polycondensation}

Abietic acid dimers (containing a small amount of trimers), were first polycondensated with different diols, using several catalysts. All the syntheses were performed applying nitrogen flow or under vaccum in order to remove the water formed during the reaction (Table 2). None of the polymerization yields high molar mass polymer; only oligomers with low dispersity were formed. The best results were obtained with titanium butoxide catalyst leading to polyesters with $M_{\mathrm{n}}$ up to $8 \mathrm{~kg} / \mathrm{mol}$. The synthesis of abietic dimethyl ester dimers and their polymerization by transeterification with the same diols, using TBD, TiOBu 4 or $\mathrm{ZnAc}$ as catalysts does not increase the molar mass of the obtained polymers. The low concentration of abietic acid isomers (2\% by GC determination) cannot explain the low reactivity toward polycondensation. Some other explainations linked to the dimer structure itself, could be proposed.

First, the lactone function may have a negative impact on the polymerization process. Indeed, during polycondensation, the opening of the lactone by the diol yields to the formation an ester and a hydroxyl groups. The latter can react with acidic functions thus modifying the stoichiometry; this scenario may explain the formation of oligomers instead of high molar mass polymers. Then, the sterically hindrance of some abietic acid dimer structures could reduce their reactivity. Therefore, the abietic acid dimer polymerization method must be adapted due to the presence of lactone and several different isomers.

Table 2 SEC data of polycondensation reactions of abietic acid dimers with decanediol, butanediol or PEG600 using different catalysts

\begin{tabular}{|c|c|ccc|}
\hline Diol & $\begin{array}{c}\text { Catalyst } \\
(\% \mathrm{~mol})\end{array}$ & $\begin{array}{c}\bar{M}_{\mathrm{n}}^{\mathrm{a}} \\
(\mathrm{g} / \mathrm{mol})\end{array}$ & $Ð$ & $\overline{D P}_{\mathrm{n}}$ \\
\hline Decanediol & $\mathrm{TiOBu}_{4}(1 \%)^{\mathrm{b}}$ & 8000 & 1.4 & 13 \\
PEG600 & TiOBu$_{4}(1 \%)^{\mathrm{b}}$ & 5000 & 1.7 & 10 \\
Butanediol & $\mathrm{TiOBu}_{4}(1 \%)^{\mathrm{b}}$ & 2400 & 1,1 & 4 \\
PEG600 & ${\mathrm{ZnAc}(1 \%)^{\mathrm{b}}}^{\mathrm{b}}$ & 2300 & 1 & 2 \\
PEG600 & $\mathrm{SbO}_{3}(1 \%)^{\mathrm{b}}$ & 1100 & 1.1 & 1 \\
PEG600 & PTSA $^{\mathrm{c}}$ & 1400 & 1.1 & 1 \\
\hline
\end{tabular}

${ }^{a}$ Determined by SEC analyses, ${ }^{b}$ Performed for $2 \mathrm{~h}$ under nitrogen at $160^{\circ} \mathrm{C}$ and then for $6 \mathrm{~h}$ at $200^{\circ} \mathrm{C}$ under vacuum, ${ }^{c}$ Performed for $1 \mathrm{~h}$ under nitrogen at $150^{\circ} \mathrm{C}$ and then for $5 \mathrm{~h}$ at $200^{\circ} \mathrm{C}$ under vacuum 
In order to decrease the steric hindrance around the reactive functions and to get around the problem of the hydroxyl group from the lactone opening, abietic acid dimer (fraction 3) was esterified with undecenol to react via ADMET polymerization, which reveals to be an efficient polymerization method ${ }^{38,39}$. The dimer was copolymerized with different ratios of undecenyl undecenoate by ADMET polymerization. Thanks to this method, the different initial dimer structures, lead to several structures of esterified dimers with the same reactivity toward ADMET polymerization since the double bond is far from the abietic acid dimer core (Scheme 2).
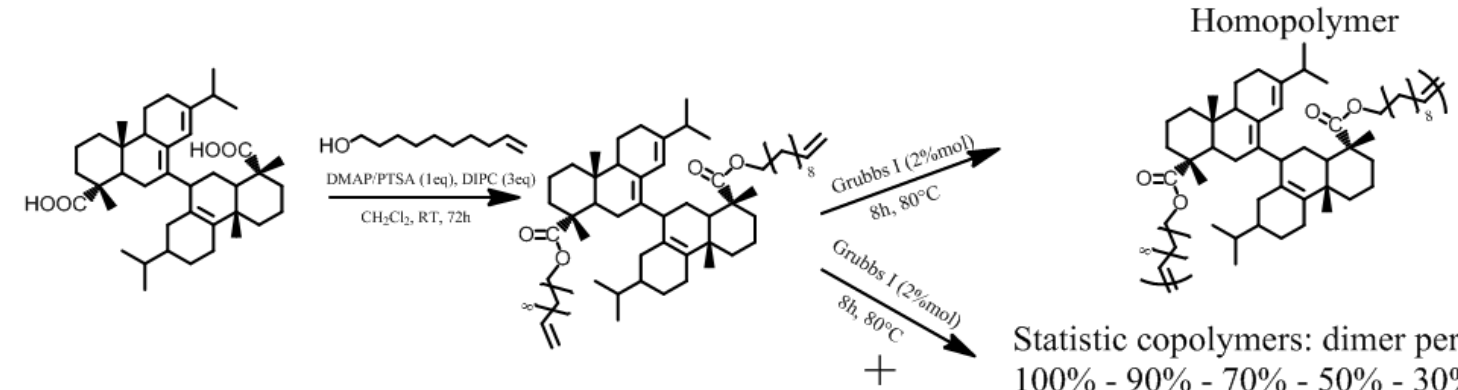

Statistic copolymers: dimer percent: $100 \%-90 \%-70 \%-50 \%-30 \%-10 \%-0 \%$

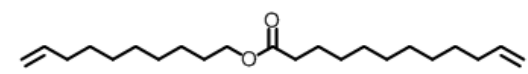

Scheme 2 Synthesis and polymerization of bisunsaturated abietic acid dimers (only one dimer form has been represented)

(1)

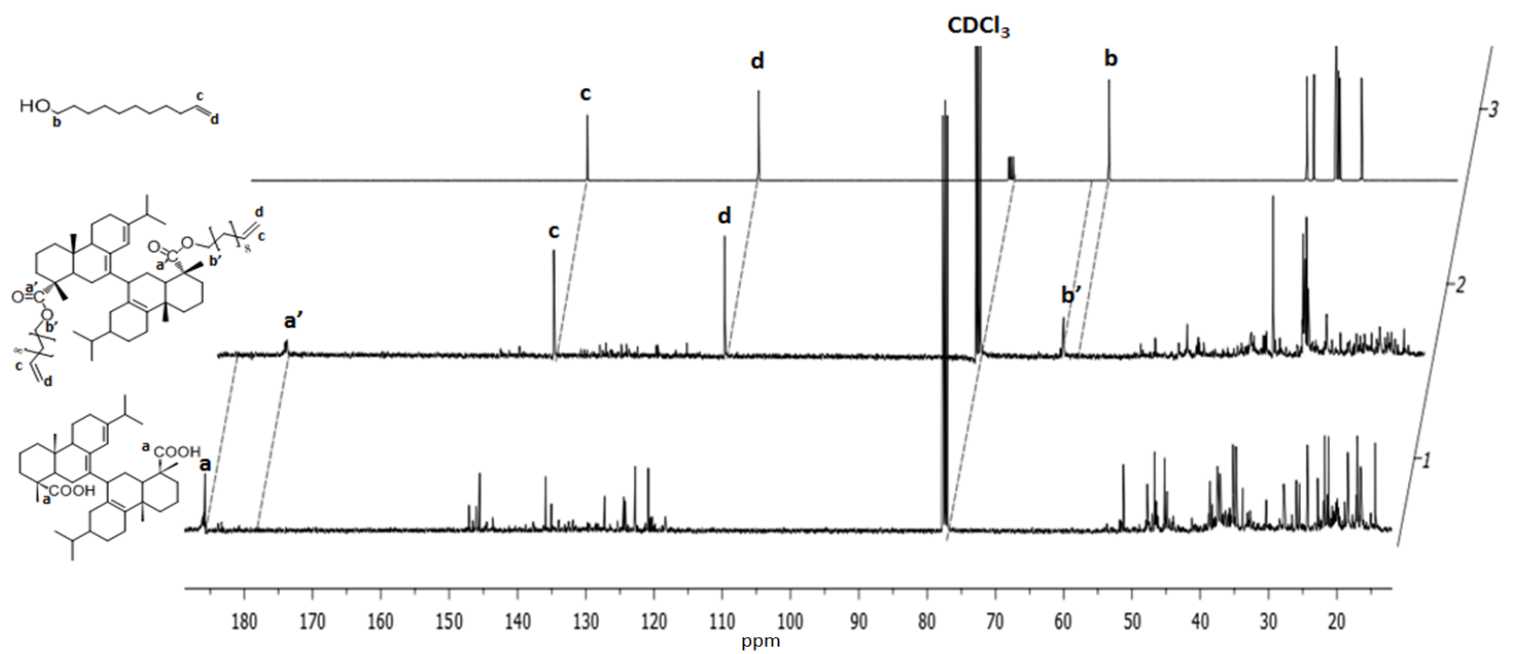

Figure $7{ }^{13} \mathrm{C}$ NMR spectra of undecenol (1), esterified abietic acid dimers (2) and abietic acid dimers (3) in $\mathrm{CDCl}_{3}$ at room temperature

The esterification of the dimer was performed under mild conditions using PTSA/DMAP catalyst. The esterification reaction between the diacid and the unsaturated alcohol is 
confirmed by ${ }^{13} \mathrm{C}$ NMR (see SD figure S9 and Figure 7). The disappearance of carbon signal assigned to the carboxylic acid function at $185 \mathrm{ppm}$ and of the lactone signals at 180 and $185 \mathrm{ppm}$ and the emergence of a new peak at $178.6 \mathrm{ppm}$ demonstrate the completion of the esterification. The spectrum of the final product presents also the peak characteristic of the terminal double bonds at $139 \mathrm{ppm}$ and $114 \mathrm{ppm}$ and the peak characteristics of the dimer remain the same. The homopolymerization by ADMET of this bisunsaturated abietic ester dimer was performed for $8 \mathrm{~h}$ at $80^{\circ} \mathrm{C}$ under vacuum and in Polarclean solvent, using Grubbs 1st generation metathesis catalyst to prevent any double bond isomerization. Besides, the copolymerization was performed in the same condition in bulk, because the undecenyl undecenoate solubilizes the abietic acid dimers. Undecenyl undecenoate was added in different proportions, from $10 \mathrm{~mol} \%$ to $90 \mathrm{~mol} \%$. The composition of the copolymers was estimated from ${ }^{1} \mathrm{H}$ NMR, using the $0.9 \mathrm{ppm}$ chemical shift characteristic from abietic acid dimer (see SD figure S10). The experimental polymer composition is in agreement with the theoritical one. From these data, the reactivity ratio of the two monomers were respectively estimated at 0.9 and 1.6 for the abietic acid ester dimer and undecenyl undecenoate, using the Mayo-lewis equation (see SD Figure S11). The compositions and features of the polymers so-formed are summarized in Table 3 ..

Below $50 \mathrm{~mol} \%$ of bisunsaturated abietic acid dimer in the monomer feed, the polymer molar mass is high, ranged from 19 to $42 \mathrm{~kg} / \mathrm{mol}$ with a dispersity around 2 (see Figure 8). For an equal feed ratio of the two comonomers, the SEC trace shows the formation of a second population eluted at a higher elution time and for higher content of bisunsaturated abietic acid dimer, only this second population with a molar mass ranged from 3.5 to $4.8 \mathrm{~kg} / \mathrm{mol}$ and a dispersity around 3, remains. The presence of this population with a lower molar mass and higher dispersity obtained for high amount of bisunsaturated abietic acid dimer could be explained by the formation of branched structures due to the participation of trimers in the polymerization course. 


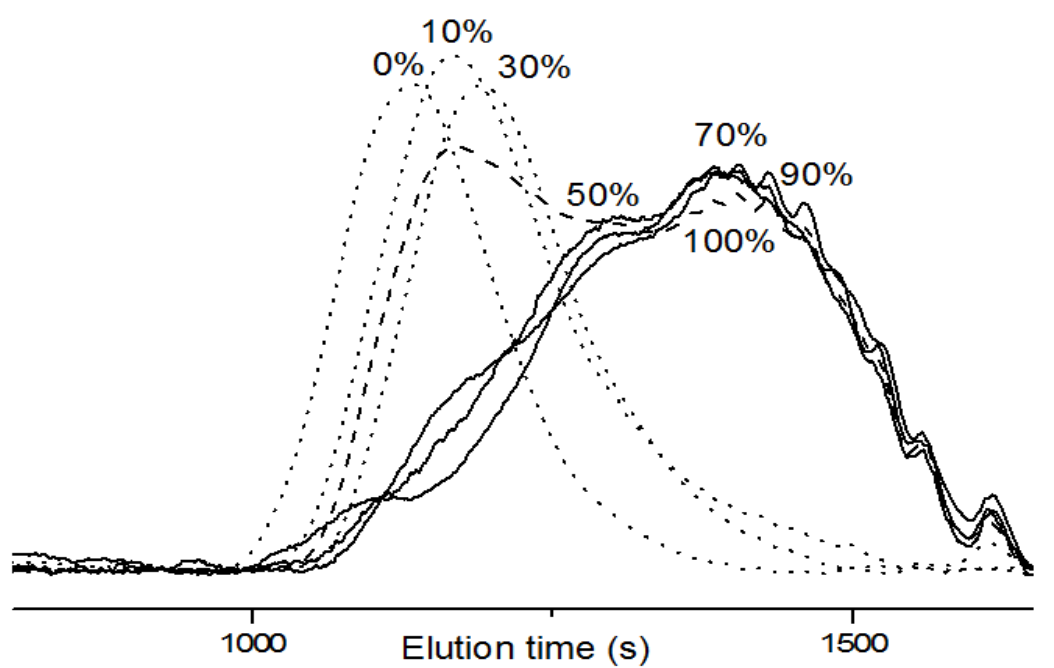

Figure 8: SEC traces of bisinsaturated abietic ester dimer/undecenyl undecenoate copolymers after ADMET polymerization (percentages of bisunsaturated abietic ester dimer are indicated)

DSC was used to examine the thermo-mechanical properties of the (co)polymers so formed (see SD figure S12). The 100\% vegetable oil based polymer presents a melting temperature $(\mathrm{Tm})$ at $55^{\circ} \mathrm{C}$. As for SEC results, DSC analyses reveal a different feature above $50 \mathrm{~mol} \%$ of abietic acid dimers incorporated. Indeed, below this thereshold, the melting temperature of the copolymers decreases progressively from $55^{\circ} \mathrm{C}$ to $43^{\circ} \mathrm{C}$ (entries 5-7 Table 3); above, the melting temperature of the copolymers remains identical to the one of the homopolymer obtained from $100 \%$ vegetable oil (entries 1-4 Table 3). This feature may be explained by the occurrence of a phase separation. The incorporation of bisunsaturated abietic acid dimer into the copolymer is confirmed by the continuous decrease of the $\Delta \mathrm{H}$ values. Indeed, abietic ester dimers introduce some disorder into the crystalline structure of the neat vegetable oil based polymers. The homopolymer of $100 \%$ of abietic acid dimer does not show any melting nor glass transition on DSC analyses. DMA analysis was thus carried out in order to further investigate the thermo-mechanical properties of the polymer. One $\mathrm{Tg}$ is observed at $102^{\circ} \mathrm{C}$ and a second one, less evident at $85^{\circ} \mathrm{C}$ which may be due to the different dimer structures or to branching thanks to the presence of trimers (see SD figure S13). TGA shows that the polymers degrade around $300^{\circ} \mathrm{C}$. 
Table 3 SEC and DSC results of bisunsaturated abietic ester dimer/undecenyl undecenoate copolymers after ADMET polymerization (percentages of bisunsaturated abietic ester dimer are indicated)

\begin{tabular}{|c|c|c|c|c|c|c|}
\hline Entry & $\begin{array}{c}\text { Abietic } \\
\text { acid } \\
\text { Dimer } \\
\text { Feed } \\
(\text { mol\%) }\end{array}$ & $\begin{array}{c}\text { Abietic acid } \\
\text { Dimer } \\
\text { Incorporated } \\
(\mathrm{mol} \%)^{\mathrm{a}}\end{array}$ & $\begin{array}{c}\bar{M}_{\mathrm{n}}^{\mathrm{b}} \\
(\mathrm{kg} / \mathrm{mol})\end{array}$ & $\boldsymbol{D}$ & $\begin{array}{l}\mathbf{T m}^{\mathrm{c}} \\
\left({ }^{\circ} \mathrm{C}\right)\end{array}$ & $\begin{array}{l}\Delta \mathbf{H}^{\mathrm{c}} \\
(\mathrm{J} / \mathrm{g})\end{array}$ \\
\hline 1 & 100 & 100 & 3.5 & 3.7 & \multicolumn{2}{|c|}{ No $\mathrm{Tm}, \mathrm{Tg}=102^{\circ} \mathrm{C}^{\mathrm{d}}$} \\
\hline 2 & 90 & 89 & 3.4 & 3.2 & 51 & 27 \\
\hline 3 & 70 & 64 & 4.1 & 2.8 & 50 & 25 \\
\hline 4 & 50 & 45 & 4.8 & 4 & 51 & 47 \\
\hline 5 & 30 & 22 & 19 & 1.7 & 43 & 51 \\
\hline 6 & 10 & 8 & 29 & 1.6 & 45 & 52 \\
\hline 7 & $\mathbf{0}$ & $\mathbf{0}$ & 42 & 2.0 & 55 & 86 \\
\hline
\end{tabular}

\section{Conclusion}

In conclusion, abietic acid dimer was successfully synthesized from abietic acid and purified $(98 \mathrm{~mol} \%)$ in reasonable yield $(35 \mathrm{wt} \%)$. An extensive study of the dimerization highlighted that not only one dimer but several different structures are formed. Moreover $40 \mathrm{~mol} \%$ of the carboxylic acid functions of the abietic acid dimer appears to be lactonized which limits its direct polycondensation. To avoid this issue, abietic acid dimers were esterified with undecenol in order to perform ADMET polymerization on the pendant double bonds. The homopolymer of bisunsaturated abietic dimers exhibits a high $\mathrm{Tg}, 102^{\circ} \mathrm{C}$ while its random copolymers with undecenyl undecenoate show a melting temperature between $40^{\circ} \mathrm{C}$ and $50^{\circ} \mathrm{C}$.

\section{Acknowledgment}

The authors thank Yannick Estevez for his help with the GC apparatus, Eric Virol for his help in flash Chromatography and Emmanuel Ibarboure and Gerard Dimier for the DMA analyses, and ANR-10-EQPX-16 XYLOFOREST.

This study was financially supported by University of Bordeaux-1, IPB and CNRS. 


\section{Notes and references}

$\uparrow$ Supplementary Data (SD) available: [Structures of abietic acid isomers, table of starting abietic acid isomer composition, table of the recrystallisation results, HPCL profile of the crude mixture after abietic acid dimerization, Flash chromatography profile of the crude mixture after dimerization, THF SEC of the 3 fractions collected by flash chromatography, GC analyses of the dimer from different abietic acid starting material, IR spectrum of the dimers, table of the number of dimers as th function of experimental conditions, GC of the dimers synthesized with different condition, ${ }^{1} \mathrm{H}$ NMR of the ADMET polymers, ${ }^{13} \mathrm{C}$ NMR spectrum of the esterified abietic acid dimers, DMA analysis of the homopolymer, DSC thermograms of the ADMET polymers].

\section{References}

1.R. T. Mathers, J. Polym. Sci., part A: Poyml. Chem., 2012, 50, 1-15.

2. R. Mülhaupt, Macromol. Chem. Phys., 2013, 214, 159-174.

3.M. J. L. Tschan, E. Brule, P. Haquette and C. M. Thomas, Polymer Chemistry, 2012, 3, 836-851.

4.L. Montero De Espinosa and M. A. R. Meier, European Polymer Journal, 2011, 47, 837852.

5. A. Gandini, Green Chemistry, 2011, 13, 1061-1083.

6. N. Peelman, P. Ragaert, B. De Meulenaer, D. Adons, R. Peeters, L. Cardon, F. Van Impe and F. Devlieghere, Trends in Food Science \& Technology, 2013, 32, 128-141.

7.C. Vilela, A. F. Sousa, A. C. Fonseca, A. C. Serra, J. F. J. Coelho, C. S. R. Freire and A. J. D. Silvestre, Polymer Chemistry, 2014, DOI: 10.1039/C3PY01213A.

8.M. Desroches, R. Auvergne, B. Boutevin and S. Caillol, OCL-oleagineux Corps Gras Lipides, 2013, 20, 16-22.

9.L. Maisonneuve, T. Lebarbe, E. Grau and H. Cramail, Polymer Chemistry, 2013, 4, 54725517.

10. K. Madhavan Nampoothiri, N. R. Nair and R. P. John, Bioresource Technology, 2010, 101, 8493-8501. 
11. Y. Lu, X. Wei, Z. Zong, Y. Lu, W. Zhao and J. Cao, Prog. Chem., 2013, 25, 838-858.

12. F. Peng, P. Peng, F. Xu and R.-C. Sun, Biotechnol. Adv., 2012, 30, 879-903

13.P. A. Wilbon, F. Chu and C. Tang, Macromolecular Rapid Communications, 2013, 34, 837.

14. K. Yao and C. Tang, Macromolecules, 2013, 46, 1689-1712.

15. PCA International Conference, Boston, Spertember 2012

16. S. Maiti, S. S. Ray and A. K. Kundu, Prog. Polym. Sci., 1989, 14, 297-338.

17. J. S. Lee and S. I. Hong, Eur. Polym. J., 2002, 38, 387-392.

18.Y. Zheng, K. Yao, J. Lee, D. Chandler, J. Wang, C. Wang, F. Chu and C. Tang, Macromol., 2010, 43, 5922-5924.

19.J. Wang, K. Yao, A. L. Korich, S. Li, S. Ma, H. J. Ploehn, P. M. Iovine, C. Wang, F. Chu and C. Tang, J. Polym. Sci., part A: Poyml. Chem, 2011, 49, 3728-3738.

20.N. J. Halbrook and R. V. Lawrence, Product R\&D, 1972, 11, 200-202.

21. S. J. Kim, B. J. Kim, D. W. Jang, S. H. Kim, S. Y. Park, J.-H. Lee, S.-D. Lee and D. H. Choi, J. Appl. Polym. Sci., 2001, 79, 687-695.

22. I. Bicu and F. Mustata, J. Appl. Polym. Sci., 2004, 92, 2240-2252.

23. A. M. Atta, A. M. Elsaeed, R. K. Farag and S. M. El-Saeed, React. Funct Polym, 2007, 67, 549-563.

24. I. Bicu and F. Mustata, J. Polym. Sci., part A: Polym. Chem, 2005, 43, 6308-6322.

25. F. Mustata and I. Bicu, Eur. Polym. J., 2010, 46, 1316-132.

26. P. Wilbon, A. L. Gulledge, B. Benicewicz and C. Tang, Green Mater., 2012, 1, 96-104.

27. T.-L. Chang, Anal. Chem., 1968, 40, 989-992.

28. P. Satturwar, S. Fulzele and A. Dorle, AAPS Pharm. Sci. Tech., 2005, 6, E649-E654.

29. A.L. Brocas, A. Llevot, C. Mantzaridis, G. Cendejas, R. Auvergne, S. Caillol, S. Carlotti, H. Cramail, Des. MonomersPolym., 2013, 17, 301-310.

30. C. Mantzaridis, A.L. Brocas, A. Llevot, G. Cendejas, R. Auvergne, S. Caillol, S. Carlotti and H. Cramail, Green. Chem, 2013, 11, 3091-3098.

31. G. Brus, L. V. Thoi and H. Francis, Peintures, Pigments, Vernis, 1953, 29-36.

32. R. G. Sinclair, D. A. Berry, W. H. Schuller and R. V. Lawrence, Product R\&D, 1970, 9, 60-65.

33. Y. Morillon, Double Liaison, 1964, 106, 91-99.

34. I. I. Bardyshev and O. D. Strizhakov, Chem. Nat. Comp., 1969, 5, 371-372.

35.R. Fujii, K. Arimoto and D. F. Zinkel, J. Am. Oil. Chem. Soc., 1987, 64, 1144-1149

36.B. Gigante, R. Jones, A. M. Lobo, M. J. Marcelo-Curto, S. Prabhakar, H. S. Rzepa, D. J. 
Williams, D. F. Zinkel, J. Chem. Soc. Chem. Comm., 1986, 1038-1039

37. R. H. Leonard, K. A. Kubitz and J. N. Rockwell, J. Am. Oil. Chem. Soc., 1965, 42, 111113.

38. T. Lebarbé, A. S. More, P. S. Sane, E. Grau, C. Alfos and H. Cramail, Macromolecular Rapid Communications, 2013, DOI 10.1002/marc.201300695.

39. T. Lebarbé, M. Neqal, E. Grau, C. Alfos and H. Cramail, Green Chemistry, 2014, DOI $10.1039 / \mathrm{c} 3 \mathrm{gc} 42280 \mathrm{a}$ 


\section{Dimerization of Abietic Acid for the Design of Renewable Polymers from} ADMET

\section{Audrey Llevot, Etienne Grau, Stephane Carlotti, Stephane Grelier and Henri Cramail}

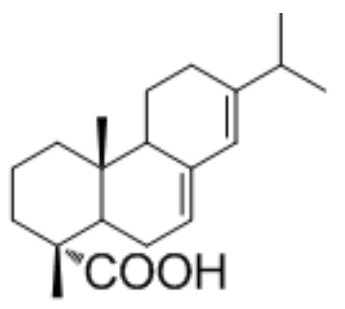<smiles>CC(C)c1ccc2c(c1)CC1C(C(=O)O)C(C)(C)CCC[C@]21C</smiles>

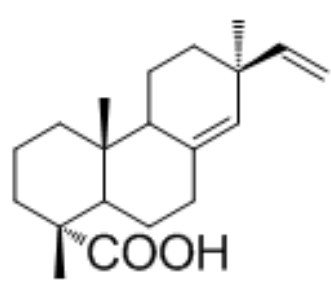<smiles>CC(C)C1=CCC2C(=C1)CC1C(C)(C)CCCC1(C)C2C(=O)O</smiles>

Abietic Acid Dehydroabietic Acid Pimaric Acid Levopimaric Acid<smiles>CC(C)C1=CC2=C(CC1)[C@@]1(C)CCC[C@](C)(C(=O)O)C1CC2</smiles><smiles>C=C[C@]1(C)CCC2C(=CC3C(C)(C)CCCC3(C)C2C(=O)O)C1</smiles><smiles>C=C[C@]1(C)C=C2CC(C(=O)O)C(C)(C)CCC2(C)[C@@H]2CCCC(C)(C)C21</smiles><smiles>CC(C)=C1C=C2CC(=O)OC3C(C)(C)CCC[C@]3(C)C2CC1</smiles>

\section{Palustric Acid Isopimaric Acid Sandaracopimaric Neoabietic Acid Acid}

Figure S1: Structure of abietic acid and its isomers

Table S1: Isomer composition of the starting abietic acids determined by integration of the vinylic protons on the ${ }^{1} \mathrm{H}$ NMR spectra: (a) 85\% pure abietic acid, (b) pre-isomerized abietic acid, (c) raw abietic acid from pine resin distillation, (d) raw abietic acid from tall oil distillation. The different isomers are identified according to Enoki, A., Isomerization and autoxidation of resin Acids. Wood research, 1976. 59/60: p. 59-57. The dimer percentage is determined by SEC.

\begin{tabular}{|c|c|cccc|}
\hline \multirow{2}{*}{ Composition } & \multirow{2}{*}{$\begin{array}{c}\text { NMR } \\
\text { characteristic } \\
\text { peak (ppm) }\end{array}$} & a & b & c & d \\
\cline { 3 - 5 } & $5.39(\mathrm{~s}), 5.77(\mathrm{~s})$ & 95 & 54 & 59 & 44 \\
\hline Abietic acid & $\begin{array}{c}6.87(\mathrm{~s}), 6.98(\mathrm{~d}), \\
7.15(\mathrm{~d})\end{array}$ & 5 & 3 & 2 & 36 \\
\hline Dehydroabietic acid & $6.39(\mathrm{~s}), 5.47(\mathrm{~s})$ & 0 & 43 & 0 & 0 \\
\hline Levopimaric/palustric acid & $5.39(\mathrm{~s})$ & 0 & 0 & 14 & 0 \\
\hline Neoabietic & - & 0 & 0 & 25 & 20 \\
\hline Dimers & & & &
\end{tabular}


Table S2: Result of the recrystallization of abietic acid after dimerization in different solvents

\begin{tabular}{cc}
\hline Solvent & Result \\
\hline Chloroform & No precipitate \\
Toluene & No precipitate \\
Heptane & No precipitate \\
Acetone & No precipitate \\
Cyclohexane & No precipitate \\
Methanol & Precipitate with the same composition as the initial product \\
Pentane/acetone & Precipitate with the same composition as the initial product \\
\hline
\end{tabular}

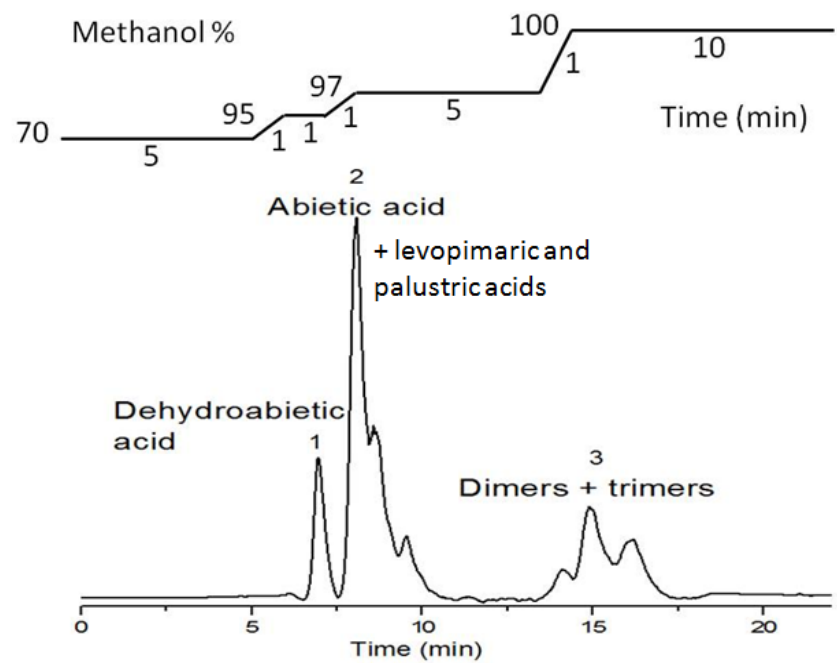

Figure S2 HPLC profile of abietic acid after dimerization, using a C18 grafted silica column, a methanol/water gradient and an ELSD detector. Top: eluent gradient program: starting from $70 \%$ hold for 5 min, increasing to $95 \%$ in $1 \mathrm{~min}$ and holding for $1 \mathrm{~min}$, increasing to $100 \%$ in $1 \mathrm{~min}$ and holding for $10 \mathrm{~min}$ 


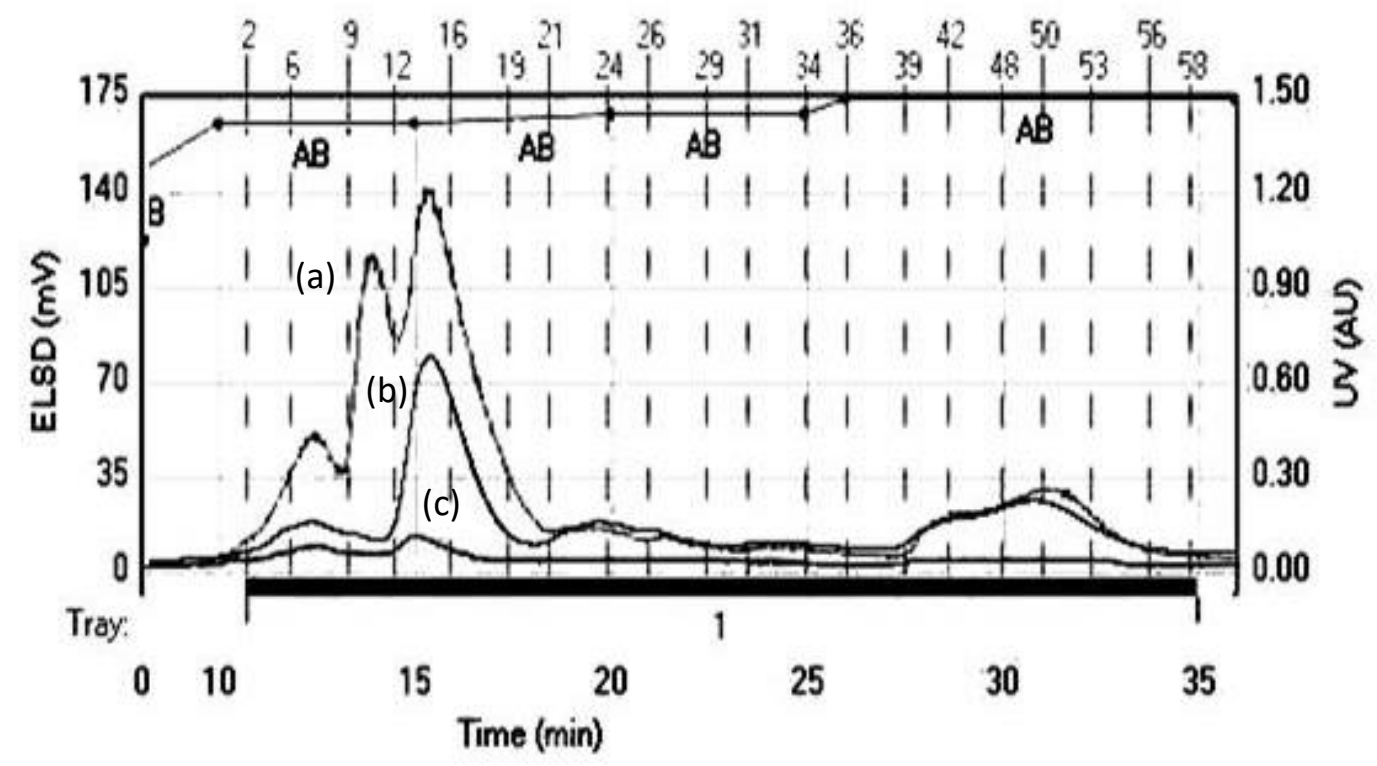

Figure S3: Flash chromatography profile after dimerization of abietic acid: (a) ELSD detector, (b) UV $254 \mathrm{~nm}$, (c) UV $280 \mathrm{~nm}$, using a water methanol gradient and a C18 grafted silica column

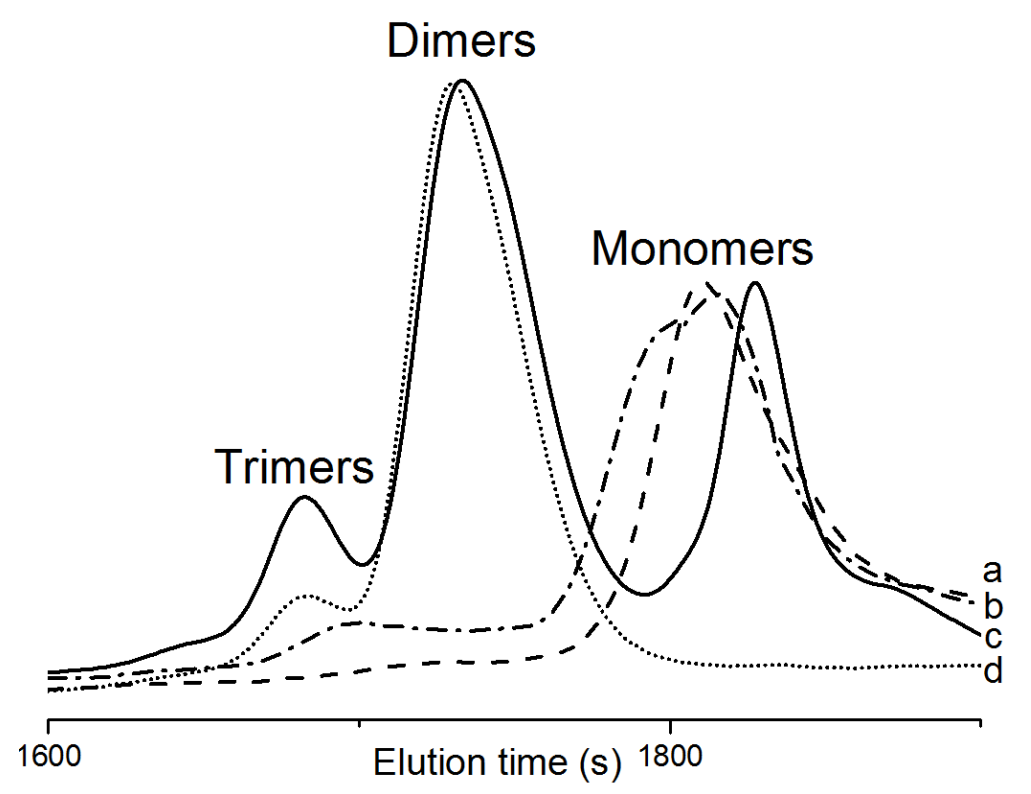

Figure S4: THF SEC analyses of (a) the fraction 1 (dash line), (b) the fraction 2 (dot dash line), (c) the fraction 3 (dot line) and (d) the crude mixture after dimerization (solid line) 


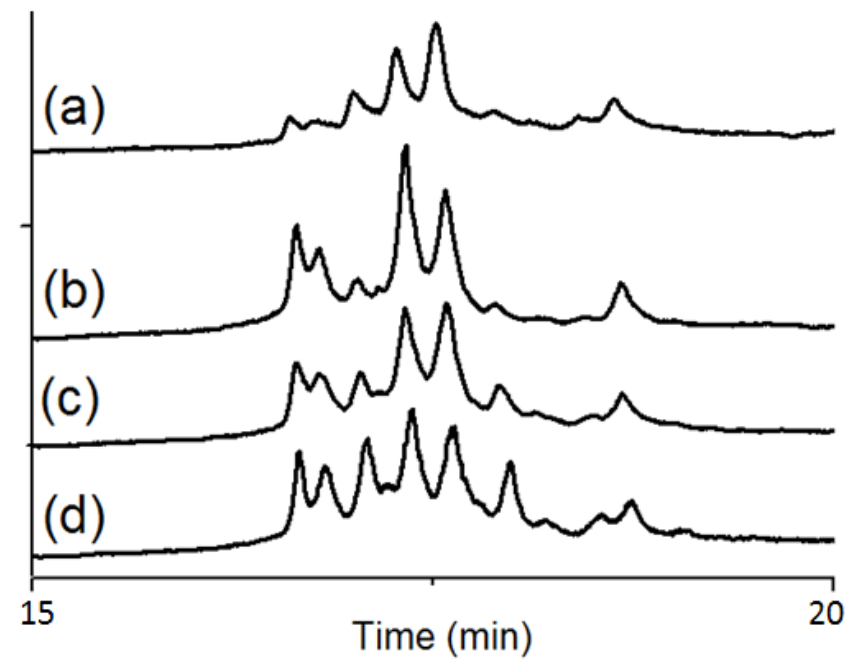

Figure S5: GC analyses of the dimers synthesized from different starting abietic acids: (a) 85\% pure abietic acid, (b) pre-isomerized abietic acid, (c) raw abietic acid from pine resin distillation, (d) raw abietic acid from tall oil distillation (using column 1)

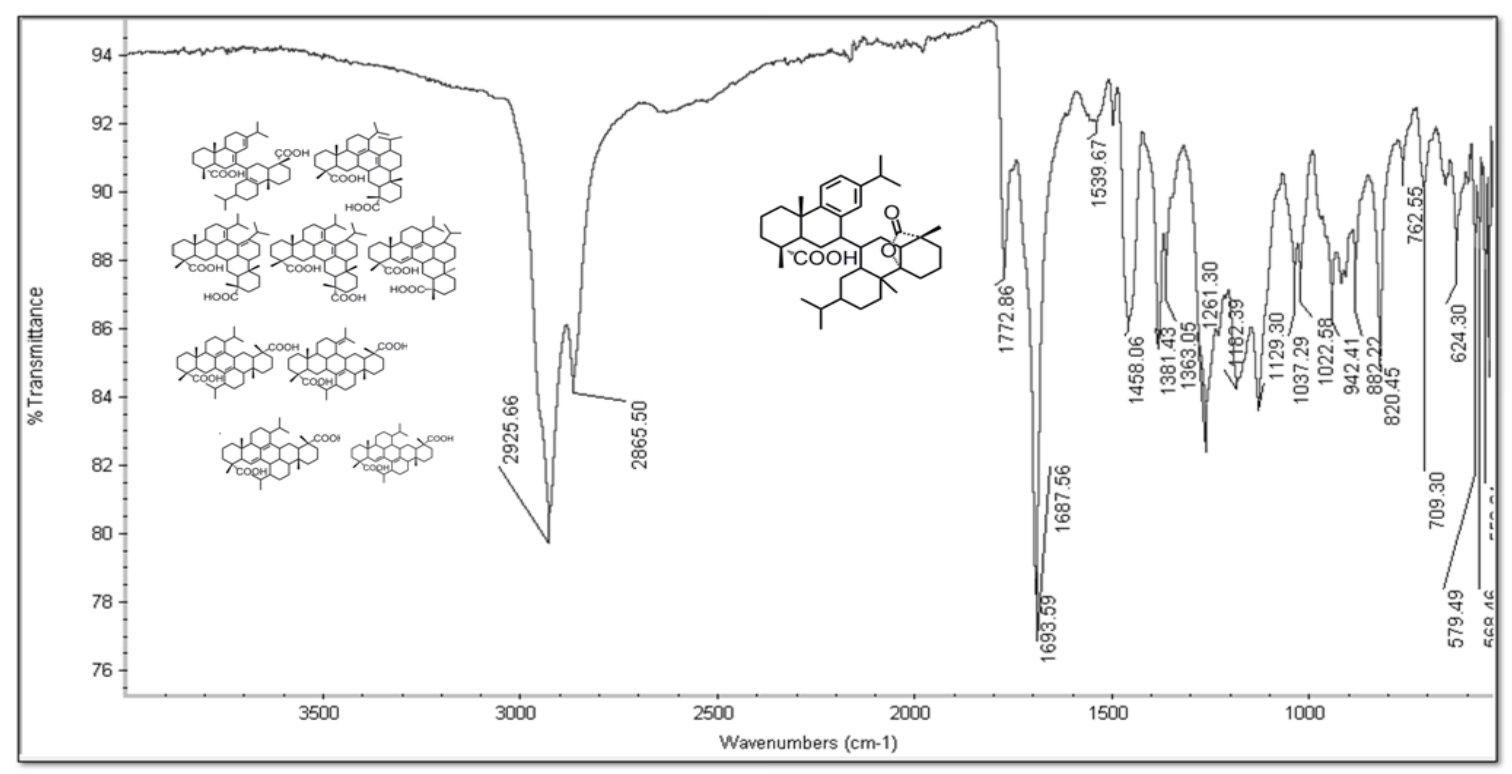

Figure S6: IR spectrum of fraction 3 (dimers + trimers of abietic acid)

Table S3: Results of the dimerization of abietic acid: number of dimers and yield as a function of experimental conditions

\begin{tabular}{ccccc}
\hline $\begin{array}{c}\text { Catalyst (molar equivalent } \\
\text { vs carboxylic acid } \\
\text { function) }\end{array}$ & Time & Temperature & $\begin{array}{c}\text { Number of } \\
\text { dimers }\end{array}$ & Yield $^{\mathrm{a}}$ \\
\hline $\mathrm{H}_{2} \mathrm{SO}_{4}(\mathbf{1 0 0 \% )}$ & $5 \mathrm{~h}$ & $45^{\circ} \mathrm{C}$ & $8^{*}$ & $57 \%$ \\
$\mathrm{H}_{2} \mathrm{SO}_{4}(\mathbf{1 0 0 \% )}$ & $8 \mathrm{~h}$ & $\mathrm{RT}$ & 13 & $35 \%$ \\
$\mathrm{H}_{2} \mathrm{SO}_{4}(\mathbf{1 0 0 \% )}$ & $6 \mathrm{~d}$ & $\mathrm{RT}$ & $10^{+}$ & $40 \%$ \\
$\mathrm{H}_{2} \mathrm{SO}_{4}(\mathbf{1 0 0 \% )}$ & $20 \mathrm{~d}$ & $0^{\circ} \mathrm{C}$ & 10 & $37 \%$ \\
$\mathrm{H}_{3} \mathrm{PO}_{4}(\mathbf{1 0 0 \% )}$ & $5 \mathrm{~h}$ & $45^{\circ} \mathrm{C}$ & $5^{*}$ & $10 \%$ \\
\hline
\end{tabular}




\begin{tabular}{lcccc}
\hline PTSA (100\%) & 20d & $0^{\circ} \mathrm{C}$ & 7 & $<5 \%$ \\
PTSA (100\%) & $5 \mathrm{~h}$ & $45^{\circ} \mathrm{C}$ & $5^{+}$ & $<5 \%$ \\
PTSA (100\%) & $3 \mathrm{~h}$ & $\mathrm{RT}$ & $3^{*}$ & $<5 \%$ \\
PTSA (100\%) & $1 \mathrm{~d}$ & $\mathrm{RT}$ & $4^{*}$ & $<5 \%$ \\
PTSA (100\%) & $6 \mathrm{~d}$ & $\mathrm{RT}$ & $5^{*}$ & $<5 \%$ \\
PTSA (100\%) & $13 \mathrm{~d}$ & $\mathrm{RT}$ & 13 & $<5 \%$ \\
PTSA (200\%) & $3 \mathrm{~h}$ & $\mathrm{RT}$ & 8 & $<5 \%$ \\
PTSA (200\%) & $6 \mathrm{~d}$ & $\mathrm{RT}$ & 9 & $<5 \%$ \\
PTSA (200\%) & $24 \mathrm{~d}$ & $\mathrm{RT}$ & $11^{+}$ & $<5 \%$ \\
PTSA (20\%) & $3 \mathrm{~h}$ & $\mathrm{RT}$ & $8^{*}$ & $<5 \%$ \\
PTSA (20\%) & $6 \mathrm{~d}$ & $\mathrm{RT}$ & $8^{*}$ & $<5 \%$ \\
PTSA (20\%) & 24d & RT & 14 & $<5 \%$ \\
PTSA (1\%) & $3 \mathrm{~h}$ & $\mathrm{RT}$ & nothing & $<5 \%$ \\
PTSA (1\%) & 6d & RT & 7 & $<5 \%$ \\
PTSA (1\%) & 24d & RT & 15 & $<5 \%$ \\
\hline
\end{tabular}

$*=1$ compound is majority

$+=2$ or 3 compounds are majority

${ }^{\text {a }}$ Determined by GC analyses using column 1

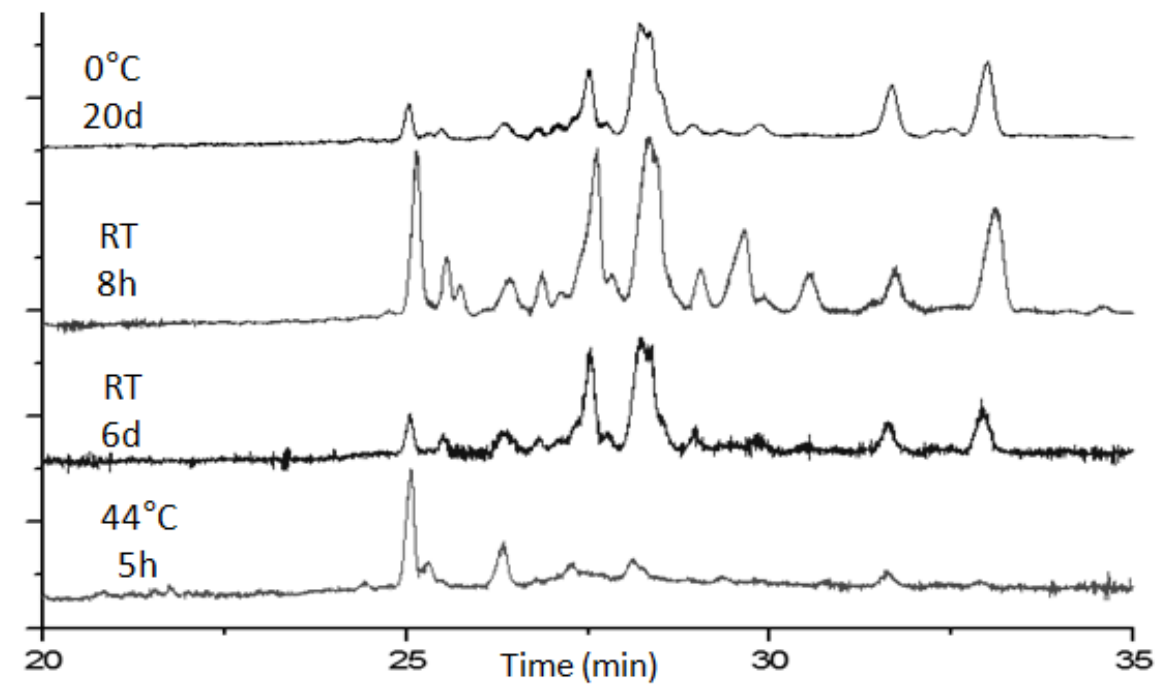

Figure S7: GC analyses after dimerization catalyzed by $\mathrm{H}_{2} \mathrm{SO}_{4}$ (using column 2) 


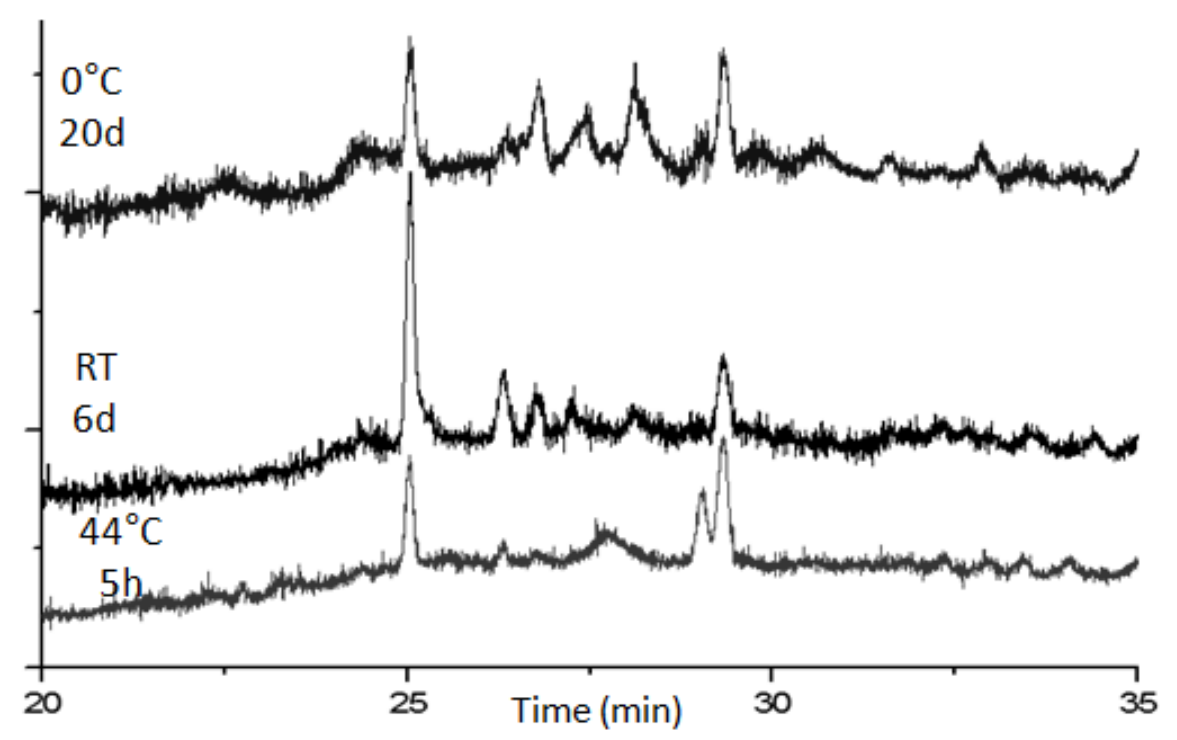

Figure S8: GC analyses after dimerization catalyzed by PTSA (using column 2)

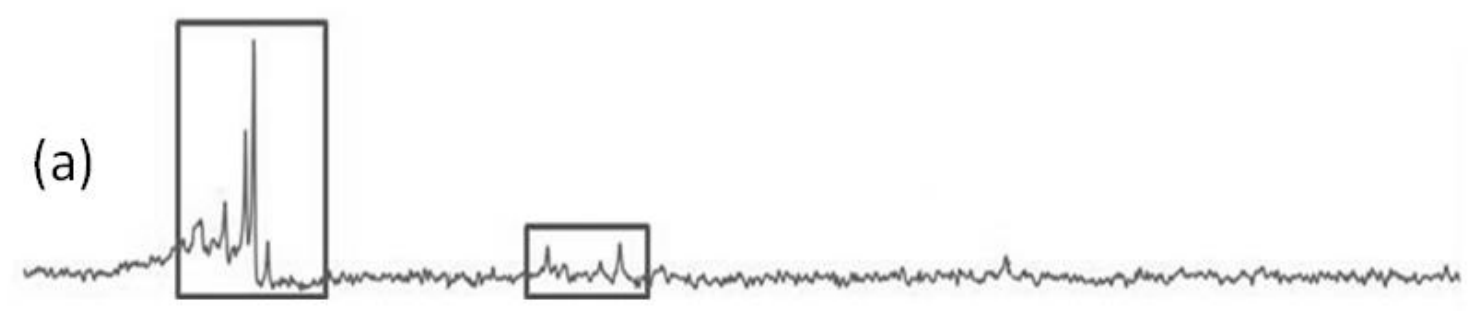

(b)

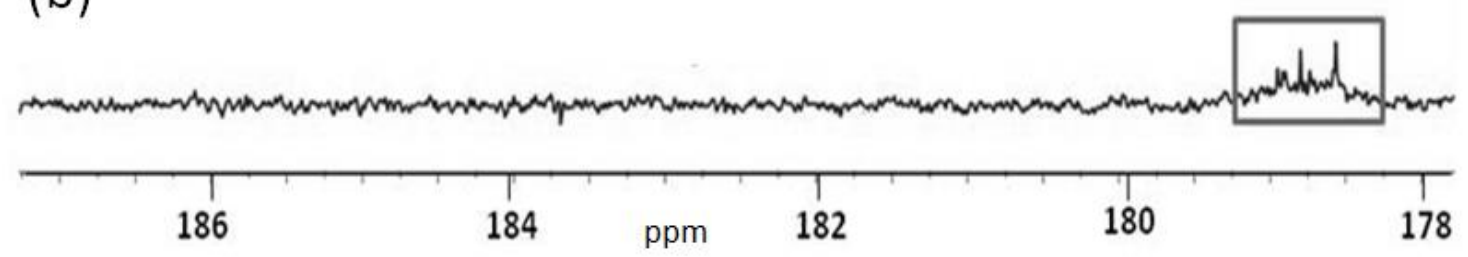

Figure S9: $\mathrm{C}=\mathrm{O}$ region ${ }^{13} \mathrm{C}$ NMR spectra of abietic acid dimers before (a) and after (b) esterification in $\mathrm{CDCl}_{3}$ 


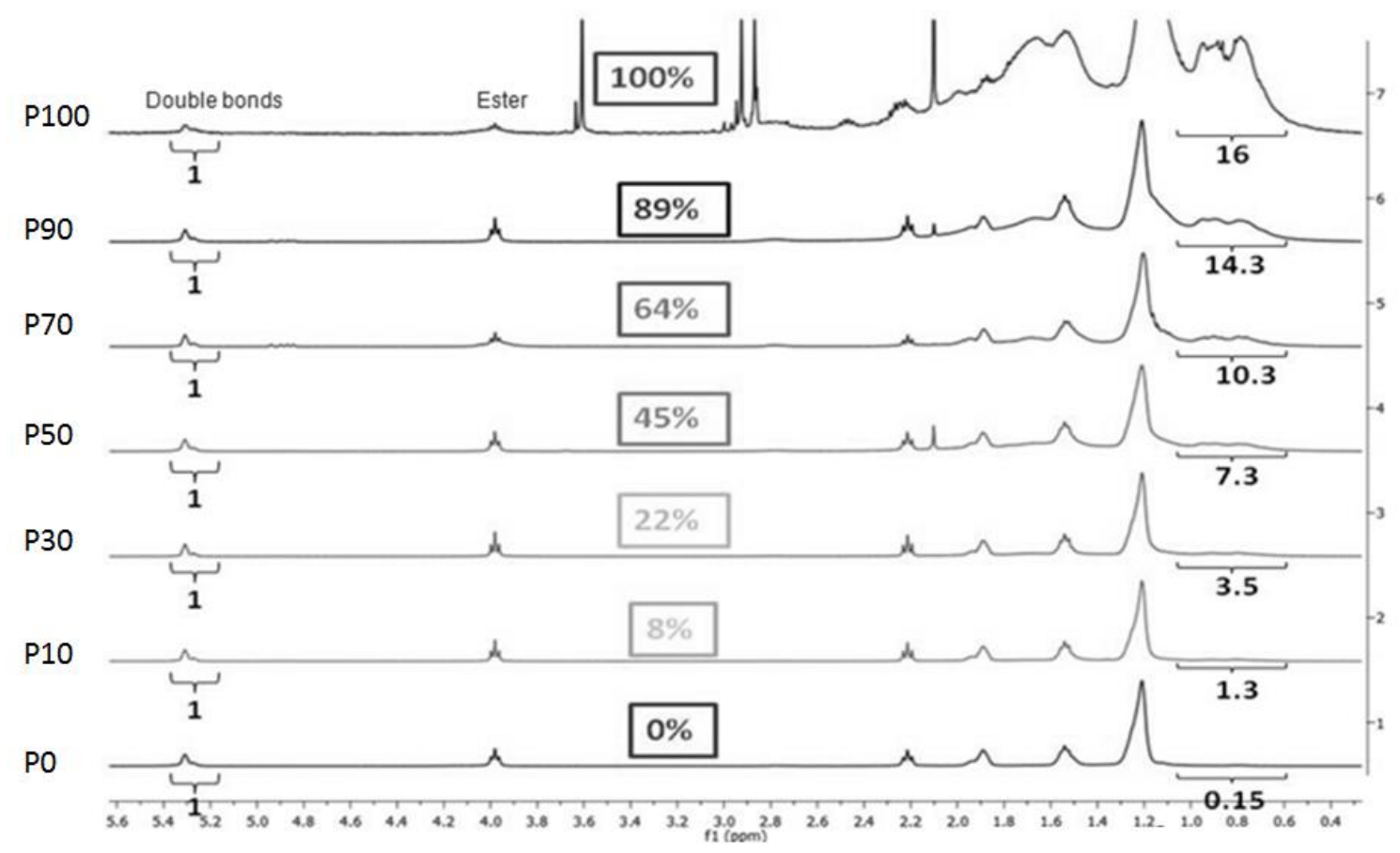

Figure S10: ${ }^{1} \mathrm{H}$ NMR spectra of the ADMET polymers, calculation of Abietic acid dimer/Undecenyl undecenoate incorporation in $\mathrm{CDCl}_{3}$ at room temperature

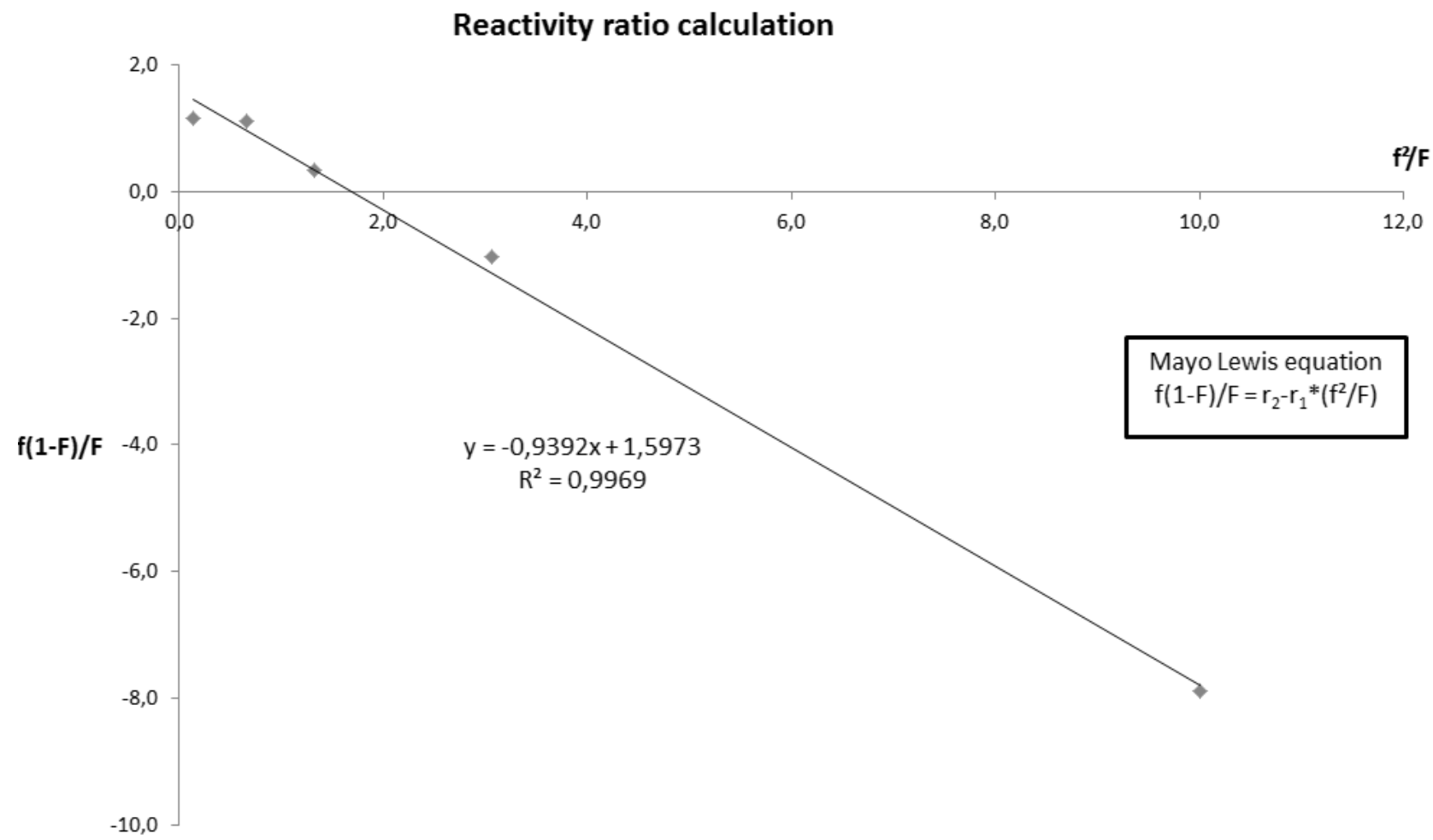

Figure S11: Reactivity ratio calculation of the abietic acid ester dimer $\left(r_{2}\right)$ and undecenyl undecenoate $\left(r_{1}\right)$ using the Mayo-Lewis equation, $\mathrm{f}=\mathrm{M}_{1} / \mathrm{M}_{2}$ in the feed and $\mathrm{F}=\mathrm{M}_{1} / \mathrm{M}_{2}$ in the copolymer 


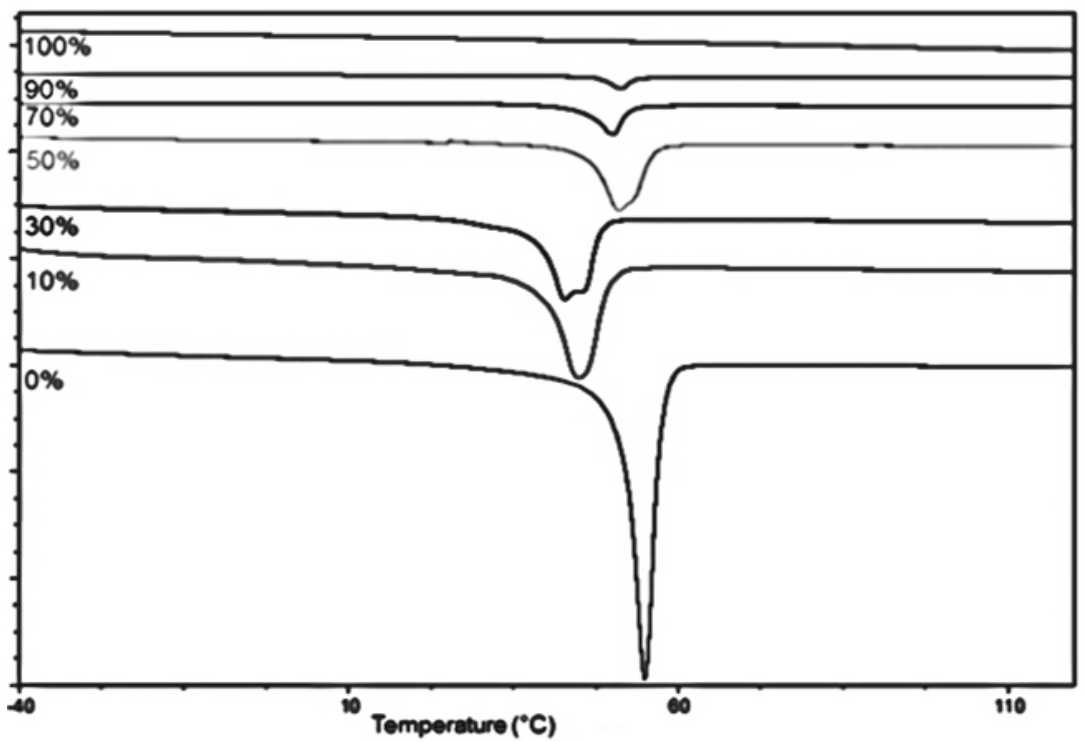

Figure S12: DSC thermograms (second heating cycle) (percentage of bisunsaturated abietic acid dimer)

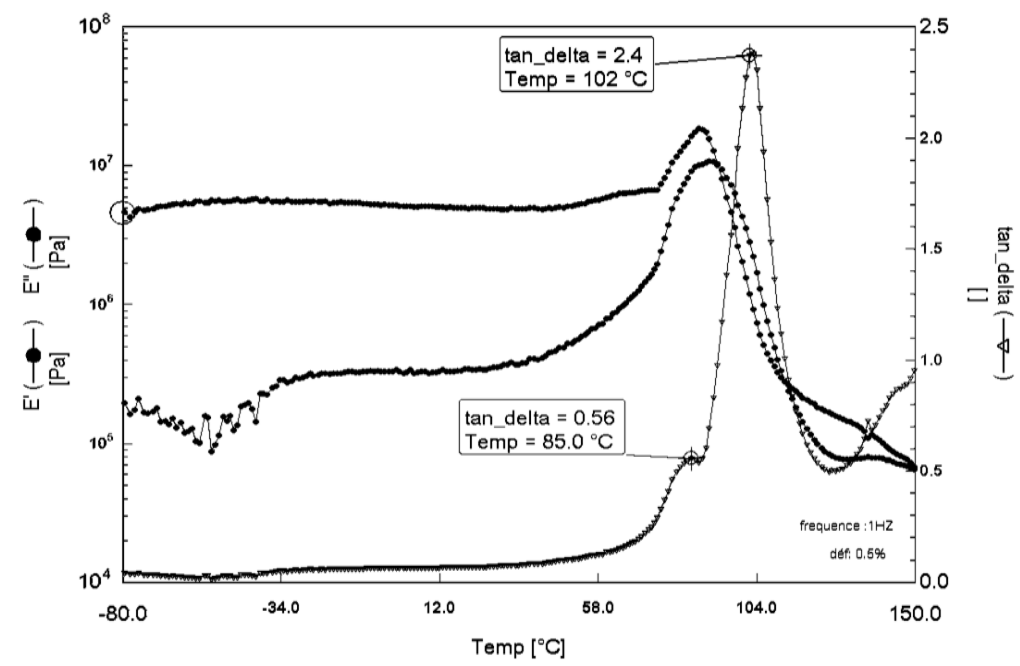

Figure S13: DMA analysis of the homopolymer abietic acid bisunsaturated ester dimer. Using compression test at $1 \mathrm{~Hz}$ from $-80^{\circ} \mathrm{C}$ to $150^{\circ} \mathrm{C}$ at $10 \mathrm{~K} / \mathrm{min}$ 